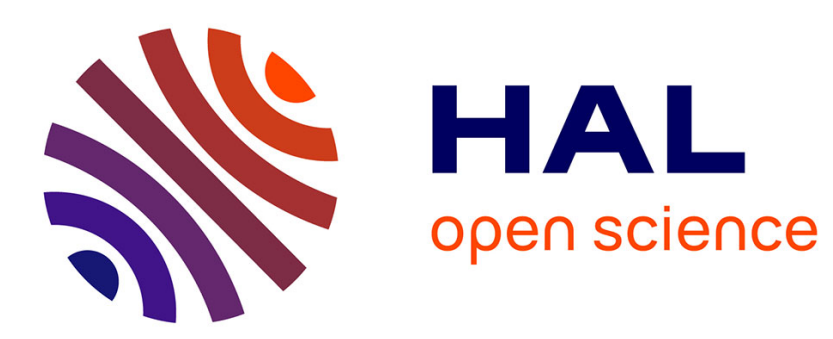

\title{
An indicator of pesticide leaching risk to groundwater
} Anna Lindahl, Christian C. Bockstaller

\section{To cite this version:}

Anna Lindahl, Christian C. Bockstaller. An indicator of pesticide leaching risk to groundwater. Ecological Indicators, 2012, 23, pp.95-108. 10.1016/j.ecolind.2012.03.014 . hal-01137065

\section{HAL Id: hal-01137065 https://hal.science/hal-01137065}

Submitted on 30 Mar 2015

HAL is a multi-disciplinary open access archive for the deposit and dissemination of scientific research documents, whether they are published or not. The documents may come from teaching and research institutions in France or abroad, or from public or private research centers.
L'archive ouverte pluridisciplinaire HAL, est destinée au dépôt et à la diffusion de documents scientifiques de niveau recherche, publiés ou non, émanant des établissements d'enseignement et de recherche français ou étrangers, des laboratoires publics ou privés. 


\title{
An indicator of pesticide leaching risk to groundwater
}

\author{
Anna M.L. Lindahla,b,*, Christian Bockstaller ${ }^{\mathrm{c}}$ \\ a Equipe Agriculture durable, INRA, BP 20507, 68021 Colmar, France \\ ${ }^{\mathrm{b}}$ Department of Soil and Environment, Swedish University of Agricultural Sciences, P.O. Box 7014, 75007 Uppsala, Sweden \\ ' INRA, UMR 1121 Nancy-Université - INRA, IFR 110, BP 20507, 68021 Colmar, France
}

\section{A R T I C L E I N F O}

\section{Article history:}

Received 23 December 2011

Received in revised form 6 March 2012

Accepted 14 March 2012

\section{Keywords:}

Data-mining

Fuzzy inference system

I-Phy indicator

MACRO model

Pesticide leaching

Preferential flow

\begin{abstract}
A B S T R A C T
Since the 90s an increasing number of assessment methods using operational tools like indicators have been proposed for environmental issues linked to pesticides, among them, groundwater contamination by pesticide transfer. To our knowledge none of these indicators address preferential flow, an important process determining pesticide leaching. The objective of this study is twofold: (i) to develop a new groundwater sub indicator for an existing indicator, I-Phy (former Ipest), that explicitly take preferential flow into account, and (ii) to test the possibility of developing an indicator by means of data-mining methods using simulations of a mechanistic model. The groundwater sub indicator developed is in the form of decision trees based on fuzzy inference systems. It was derived through neuro-adaptive learning on data sets from simulations running the process-based MACRO model. Unlike the previous version, the new indicator considers preferential flow, climatic differences and differences in soil texture with depth. Other benefits are less dependency on expert knowledge and the possibility to integrate a broad range of conditions.
\end{abstract}

(C) 2012 Elsevier Ltd. All rights reserved.

\section{Introduction}

The intensive use of pesticides in modern agriculture have had an impact on human health, living organisms, ecosystem functioning, water quality, etc. (Perrin, 1997). During the last two decades, this has led to a growing concern among different groups of stakeholders. Development of different kinds of solutions, such as new technologies, new resistant cultivars, redesign of plant protection systems and cropping systems, is on the agenda to reduce the dependency on chemicals (e.g. ENDURE, 2011). A general agreement is that the reduction of pesticide risks in conventional agriculture goes hand in hand with the development of assessment tools of pesticide risk and impact (Bockstaller et al., 2009). Since the 90 s an increasing number of assessment methods using operational tools like indicators have been proposed for environmental issues linked to pesticides. These indicators are more advanced than the former assessments based solely of pesticides weight and volume (Levitan, 2000). To our knowledge, none of the existing pesticide environmental risk indicators address preferential flow as a mechanism involved in groundwater contamination (see e.g. reviews by Reus and Leendertse, 2000; Maud et al., 2001; Bockstaller et al., 2009). Nevertheless, preferential flow is important in a range of

\footnotetext{
* Corresponding author. Present address: Department of Soil and Environment, Swedish University of Agricultural Sciences, P.O. Box 7014, 75007 Uppsala, Sweden. Tel.: +4618 671169; fax: +4618673156.

E-mail address: anna.lindahl@slu.se (A.M.L. Lindahl).
}

different soils (Flury, 1996) and occurs in structured soils through macropores (Beven and Germann, 1982), as finger flow in water repellent sandy soils (Ritsema et al., 1993; Dekker and Ritsema, 1996) or layered soils (Hill and Parlange, 1972), or as funnel flow (Kung, 1990). Simulation studies have shown a reduced influence of pesticide properties on leaching in the presence of macropore flow (Larsson and Jarvis, 2000). In field studies, the simultaneous arrival of various pesticides in tile drains despite their different sorption characteristics (Kladivko et al., 1991; Traub-Eberhard et al., 1994) has been attributed to preferential flow. In situations of preferential flow, indicators based on a simple index considering pesticide properties only are unable to correctly assess the fate of pesticide considered as 'non-leachable'. An example is the GUS-index (Gustafson, 1989), commonly used for estimating the leachability of pesticides through weighing the effects of the partition coefficient to soil organic carbon $\left(K_{\mathrm{oc}}\right)$ and the degradation half-life $\left(\mathrm{DT}_{50}\right)$ of the pesticide. Preferential flow occurring shortly after application can cause high losses even for fast degrading pesticides. Furthermore, experimental (Reichenberger et al., 2002) and modeling evidence (McGrath et al., 2008) suggest that rapid preferential transport increases with increasing sorption capacity. This may be due to that weakly sorbing pesticides will be transported away from the soil surface by matrix flow following small amounts of gentle rain. At such weather conditions, more strongly sorbing pesticides will be more susceptible for transport by preferential flow in case of a rain storm at a later date since they are retained in the soil near the surface for a longer period of time (McGrath et al., 2008). Soil water content at the time of application and the subsequent 
precipitation pattern are thus important factors since they regulate whether preferential flow is triggered or not and to what extent. Approaches for determining worst-case pesticide properties for a specific soil, with respect to leaching, therefore need to take into account not only pesticides properties but also factors determining and regulating preferential flow.

Deterministic simulation models of pesticide fate and transport in the soil that account for macropore flow are available (e.g. MACRO; Larsbo et al., 2005; Köhne et al., 2009). However, extensive data requirements make these models difficult, or impractical, to use for site-specific exposure assessments. A way to overcome this major drawback could be to derive indicators from complex dynamic models using meta-modeling approaches (Piñeros Garcet et al., 2006; Bockstaller et al., 2008a). A major advantage of such model-based indicators is that the causes of an impact can be deduced (i.e., main factors responsible for an effect can be identified) when simulating different scenarios. In the development of such meta-models it should be considered that simulation models of pesticide fate and transport are non-linear in their response to changes in soil and pesticide parameters. Simulation metamodels using linear regression techniques are therefore likely to fail (Bouzaher et al., 1993). Approaches addressing non-linear relations in meta-modeling are however available. Examples of meta-modeling techniques used to assess the processes of pesticide fate and transport in the soils are neural networks (Stenemo et al., 2007) and look-up tables of the MACRO model (Holman et al., 2004), and the fitting of simulations to a simple mathematical function (as done by Bouzaher et al. (1993) for the RUSTIC modeling system (Dean et al., 1989)).

I-Phy (former name Ipest) (van der Werf and Zimmer, 1998; Bockstaller et al., 2008b) is a well-documented pesticide indicator and a constituent of the INDIGO method for assessing sustainability of agricultural systems (Bockstaller et al., 1997, 2009). It has been compared to other European indicators (Reus et al., 2002), adapted and implemented in different situations as well as in research projects (Bues et al., 2004; Arregui et al., 2010; Chikowo et al., 2009) and more than 130 extensions projects (e.g. Novak et al., 2009). But, in common with many other indicators, its groundwater module for assessing pesticide leaching risk neglects preferential flow and heavily relies on the GUS-index. Consequently, there is a risk that I-Phy underestimate the pesticide leaching risk for soils prone to preferential flow.

The objective of this study is twofold: (i) to develop a new groundwater sub indicator of I-Phy addressing in an explicit way preferential flow, and (ii) to test the approach stated by Bockstaller et al. (2008a), i.e., developing an indicator by means of data-mining methods using simulations of a mechanistic model. To achieve these objectives, we decided to base the new indicator on simulations carried out with the process-based macropore flow model MACRO (Jarvis, 1994; Larsbo et al., 2005). To avoid creating a 'black box' of statistical empirical functions lacking any clear meaning, as can be the product of meta modeling (e.g. Piñeros Garcet et al., 2006; Stenemo et al., 2007), we chose to keep the I-Phy structure which is in the form of decision trees using linguistic rules that are easy to understand and free from complex mathematical functions. We also decided to apply fuzzy subsets for continuous input variables to avoid knife-edge effects at the class boundaries (Prato, 2005). We thereby retained the design choice of the original I-Phy indicator as it also is a fuzzy inference system. A data-mining method of neuro-adaptive learning type was applied to allow for the parameterization of the many membership functions and rules of the inference system developed. The resulting scores of the new indicator were compared to that of the former for some common scenarios of pesticide application in France.

\section{Materials and methods}

\subsection{Indicator design}

\subsubsection{Overview of the former indicator}

I-Phy (van der Werf and Zimmer, 1998; Bockstaller et al., 2008b) is an expert system for calculating indicators reflecting the potential environmental impact of the application of a pesticide in a field crop. The model is based on literature, experimental data and expert knowledge, addressing uncertainty using a fuzzy logic approach. I-Phy comprise several modules (e.g. for estimating the risk of contamination of surface waters or the air) of fuzzy inference system type. The modules are structured in the form of decision trees representing the extreme situations of combinations of two fuzzy subsets; favorable and unfavorable states of the variables. A membership function is associated with each variable of the decision tree so that a fuzzy class can be calculated for variable values that fall between the extremes. The final output of each module is an indicator score calculated using the Sugeno's inference method (Sugeno, 1985) also implemented by van der Werf and Zimmer (1998) as well as by Fragoulis et al. (2009). A detailed description of I-Phy, with calculation examples, is given in van der Werf and Zimmer (1998). In the latest version of I-Phy (Bockstaller et al., 2008b), the indicator scores range on a scale of environmental performance, from 0 (representing a high-risk scenario) to 10 (representing a no-risk scenario), with an acceptable risk defined at indicator score 7. The same scale is used for all indicators included in the INDIGO assessment method (Bockstaller et al., 1997, 2009). The choice of the general scale of INDIGO was driven by the need to provide users with a scale that is easy to understand. To improve the farmers' perception of the assessment methods, a positive scale was chosen rather than a risk scale. The reference value of 7 allows to set an operational and acceptable (better than average) target which is not the "ideal" target of "zero impact", sometimes impossible to reach in short term.

\subsubsection{Indicator design work flow}

The development of the groundwater indicator module (referred to as the indicator) consisted of the following four steps (see Fig. 1):

\section{Step 1. Selecting relevant input variables:}

The selection of variables is an important step. All variables, which have a significant impact on the pesticide dynamics relevant for the specific conditions for which the developed indicator is to be applied, need to be identified. Potential input variables were selected according to our expert knowledge of the pesticide leaching process and pesticide use, soil and cropping conditions within agricultural systems in France. Furthermore, the input variable values should be readily available in databases (e.g. pesticide properties) or known to the end users (e.g. information on soil properties, pesticide application, climate, etc.). This criterion facilitates the use of the indicator. To give insight into how pesticide loss relates to the input variables, it is also desirable that the indicator is easy to understand and interpret. A vast number of input variables would produce overly complex decision trees. We therefore strive to limit their number. The variables taken into consideration when developing the indicator are summarized in Table 1. Different types of cropping are also considered but are excluded from Table 1 since the crops are fixed to the variable season of application (i.e., spring application on maize and winter or autumn application on winter wheat). All in all, the MACRO model was parameterized for five discrete and five continuous variables. The assessment of the sensitivity of several MACRO input variables in a pre-study of 1944 simulation runs enabled us to reject some of them. 
$\underline{\text { Step } 1}$

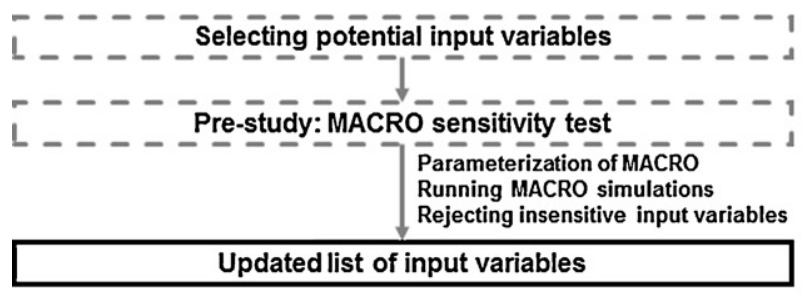

Step 2

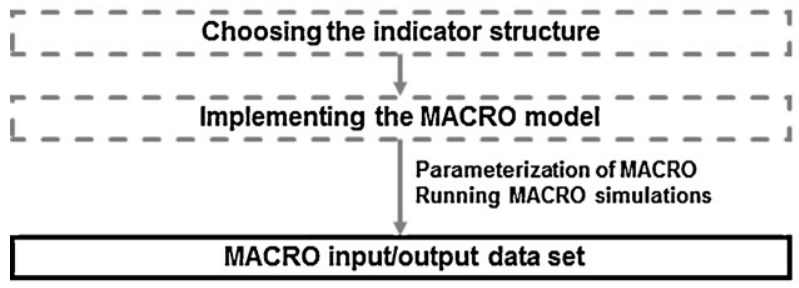

\section{Step3}

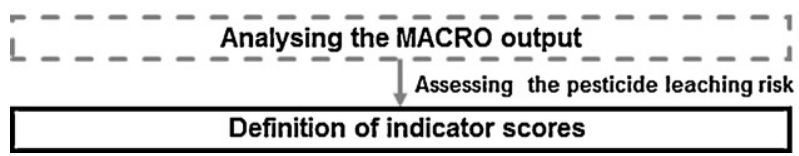

Step 4

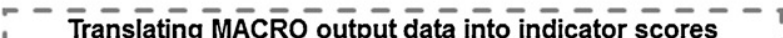
L _ _ _ _ _ _ _ _ _ _ _ _ _ _ _ _ _ _ _ - . 1 Inputloutput indicator learning data set

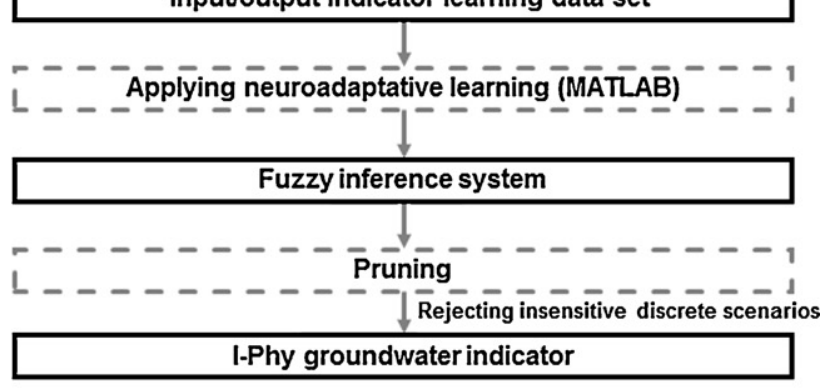

Fig. 1. The work process flowchart. Actions in squares with gray dotted borders and outputs in squares with black solid borders.

Step 2. Choosing the structure of the indicator, setting up the simulation scenarios and running the mechanistic model:

To limit the complexity of the indicator, a decision was made to treat some input variables as discrete (e.g. season of application and climatic zone). As a consequence, the structure of the indicator consist of a number of trees that the user has to choose from depending on the scenario reflected by the combination of these variables (e.g. spring application in southern France). The MACRO model was parameterized using the list of potential input variables (established in step 1) using pedotransfer functions when necessary, reasonable worst-case assumptions and default values. For each continuous variable, we selected values that we a priori considered to correspond to favorable and unfavorable conditions in regards of pesticide loss (see Table 1 ). A number of intermediate values were also selected within these intervals. A broad range of different combinations of continuous input variable values could thereby be executed for all discrete scenarios possible. The details of this step are given in Section 2.3 below.

Step 3. Assessing the pesticide leaching risk:

Table 1

The selected potential input variables and their ranges. ${ }^{a}$

\begin{tabular}{|c|c|c|}
\hline Variable & Type & Variable values \\
\hline Depth of soil profile $(\mathrm{cm})$ & Continuous & $40-100$ \\
\hline$f_{\text {oc }}(\%)$ & Continuous & $1-3$ \\
\hline Stoniness ${ }^{\mathrm{b}}(\%)$ & Continuous & $0-10$ \\
\hline $\mathrm{DT}_{50}$ (days) & Continuous & $5-60$ \\
\hline$K_{\mathrm{oc}}\left(\mathrm{cm}^{3} \mathrm{~g}^{-1}\right)$ & Continuous & $27-600$ \\
\hline Topsoil texture & Discrete & Coarse, medium, fine \\
\hline Subsoil texture & Discrete & Coarse, medium, fine \\
\hline Tillage $^{c}$ & Discrete & Primary tillage, no tillage \\
\hline Season of application & Discrete & Winter, spring, autumn \\
\hline Climatic zone $\mathrm{d}^{\mathrm{d}}$ & Discrete & $1,2,11$ \\
\hline
\end{tabular}

${ }^{a} f_{\text {oc }}=$ topsoil organic carbon content, $\mathrm{DT}_{50}=$ degradation half-life, $K_{\mathrm{oc}}=$ partition coefficient to soil organic carbon.

b Applies to coarse textured soils.

c Applies to topsoils of medium and fine texture.

d FOOTPRINT climatic zones (see Centofanti et al., 2008).
It is necessary to define what the indicator scores correspond to in regards of pesticide leaching risk to groundwater. We made two choices regarding the meaning of the indicator scores:

(i) We set the acceptable level of pesticide loss to $0.1 \mathrm{~g} \mathrm{ha}^{-1}$, corresponding to the indicator score of 7 (Table 2). This level of pesticide loss may generate a concentration of $0.1 \mu \mathrm{g} \mathrm{L}^{-1}$ (corresponding to the EU drinking water limit (European Union, 1991)) for a drainage of $100 \mathrm{~mm}$. This is probably a conservative assumption if we assume that in most situations, drainage varies between 50 and $650 \mathrm{~mm}$ (Choisnel and Noilhan, 1995).

(ii) We set the relationship between the pesticide loss and the value of the indicator score so that two indicator score units correspond to a $\log _{10}$ change in pesticide loss. This gives an indicator covering a broad range of possible pesticide loads scoring 0 for pesticide losses of $550 \mathrm{~g} \mathrm{ha}^{-1}$ or more to 10 for losses of $0.0055 \mathrm{~g} \mathrm{ha}^{-1}$ or less. This approach is justified by the uncertainty of model outputs. The point here is not to detect minor differences in pesticide loss but rather to assess the order of the loss (Lewis et al., 1999).

Step 4. Deriving the fuzzy inference system:

The input/output data sets of 4752 MACRO simulations were used to estimate membership functions representative of the features of the data. However, the output of the MACRO model had to be translated to indicator scores first, producing input/output indicator data learning set. A fuzzy inference system of Sugeno-type

Table 2

Relationship between pesticide loss and indicator scores.

\begin{tabular}{ll}
\hline Pesticide losses $\left(\mathrm{g} \mathrm{ha}^{-1} \mathrm{y}^{-1}\right)$ & Associated score \\
\hline Less than 0.0055 & 10 \\
From 0.0055 to 0.01 & From 10 to 9 \\
From 0.01 to 0.1 & From 9 to 7 \\
From 0.1 to 1 & From 7 to 5 \\
From 1 to 10 & From 5 to 3 \\
From 10 to 100 & From 3 to 1 \\
From 100 to 550 & From 1 to 0 \\
More than 550 & 0 \\
\hline
\end{tabular}


was created through applying the MATLAB Fuzzy Logic Toolbox (MathWorks, 2002) algorithms for neuro-adaptive learning to the data set. A Sugeno inference system is well suited for modeling non-linear systems (Sugeno, 1985; Babuška and Verbruggen, 2003). During the learning process, the parameters associated with the membership functions and associated rules are adjusted according to a chosen error criterion. Two membership functions are derived for each input variable, one for determining the degree to which the input belongs to the unfavorable fuzzy set and the other for determining the degree of membership to the favorable fuzzy set. The possible combinations of favorable and unfavorable values of the indicator input variables each make up a rule. The output of each rule is multiplied by a weight $(w)$ that reflects its strength within the fuzzy inference system for a specific combination of variable values. The output, of the fuzzy inference system, $I_{\text {base, }}$, is the weighted average (the only option for the neuroadaptive learning algorithm of the MATLAB Fuzzy Logic Toolbox) of all rule outputs $\left(z_{i}\right.$ to $\left.z_{N}\right)$ :

$I_{\text {base }}=\frac{\sum_{i=1}^{N} w_{i} \cdot z_{i}}{\sum_{i=1}^{N} w_{i}}, \quad$ for $0 \geq I_{\text {base }} \leq 10$.

A unique fuzzy inference system was developed from 44 simulations for every combination of discrete variables influencing the pesticide leaching. However, some combinations could be pruned away since some data sets were validated by fuzzy inference systems based on different data sets (in regards of discrete variables). The number of fuzzy inference systems could thereby be reduced. As pruning criterion, a root mean square error (rmse) $\leq 0.5$ indicator scores was judged as a sufficient match between a data set and an inference system.

\subsection{Simulation model}

MACRO (Jarvis, 1994; Larsbo et al., 2005) is a one-dimensional dual permeability model simulating a full water balance and the fate and transport of pesticides at the column scale. The pore system is divided into two domains, the micropore and the macropore domain, which have their own solute concentration, pressure head, water content and hydraulic conductivity. In the micropore domain, water flow is described using the Richard's equation (Richards, 1931). Water flow in the macropore domain is described by a modified kinematic wave equation, which contains two parameters, macropore conductivity and an exponential reflecting macropore connectivity and tortuosity (Germann, 1985). The water retention function is described by a modified form of the van Genuchten function (van Genuchten, 1980). The advection-dispersion equation (van Genuchten and Wierenga, 1976) is used to describe solute transport in the micropores. An advective flow of solute, neglecting dispersion, is used for the macropores. Pesticide sorption is described using a Freundlich isotherm, while degradation is described using first order kinetics, with the rate coefficient given as a function of soil temperature and moisture content (Boesten and van der Linden, 1991). Approximate first-order expressions are used to calculate water transfer from the macropores to the micropores and solute exchange between the two domains. This transfer is controlled by the strength of the macropore flow, described by the effective diffusion pathlength which is an 'effective' parameter reflecting soil structural development.

\subsection{Simulation scenarios and parameterization}

The MACRO model was parameterized from soil organic carbon content, soil texture, pesticide properties, crop properties, tillage operations and climatic properties. A detailed description of the
Table 3

The eight climatic factors defining the climatic zoning of Europe within the FOOTPRINT project, and their mean values for grid cells within each climatic zone.

\begin{tabular}{|c|c|c|c|c|}
\hline \multirow[t]{2}{*}{ Climatic factor } & \multicolumn{4}{|c|}{ Climatic zone } \\
\hline & 1 & 2 & 6 & 11 \\
\hline $\begin{array}{l}\text { Mean April to June } \\
\text { temperature }\left({ }^{\circ} \mathrm{C}\right)\end{array}$ & 13.4 & 11.5 & 5.9 & 13.0 \\
\hline $\begin{array}{l}\text { Mean September to November } \\
\text { temperature }\left({ }^{\circ} \mathrm{C}\right)\end{array}$ & 11.7 & 9.8 & 4.8 & 13.0 \\
\hline $\begin{array}{l}\text { Mean October to March } \\
\text { precipitation }(\mathrm{mm})\end{array}$ & 485 & 368 & 765 & 606 \\
\hline $\begin{array}{l}\text { Mean annual precipitation } \\
\quad(\mathrm{mm})\end{array}$ & 936 & 733 & 1695 & 942 \\
\hline $\begin{array}{l}\text { Number of days (April to June) } \\
\text { where total precipitation } \\
>2 \mathrm{~mm}\end{array}$ & 30.5 & 32.5 & 36.5 & 27.4 \\
\hline $\begin{array}{l}\text { Number of days (April to June) } \\
\text { where total precipitation } \\
>20 \mathrm{~mm}\end{array}$ & 2.6 & 1.5 & 3.3 & 1.7 \\
\hline $\begin{array}{l}\text { Number of days (April to June) } \\
\text { where total precipitation } \\
>50 \mathrm{~mm}\end{array}$ & 0.1 & 0.1 & 0.1 & 0 \\
\hline $\begin{array}{l}\text { Number of days (September to } \\
\text { November) where total } \\
\text { precipitation }>20 \mathrm{~mm}\end{array}$ & 3.3 & 2.1 & 3.2 & 3.1 \\
\hline
\end{tabular}

Data from Blenkinsop et al. (2008).

parameterization of soil physical and hydraulic properties is given in Appendix A. The simulation period was 26 years, in which the first six years are used as a warming up period in order to minimize the influence of the initial conditions, and the last 20 years are used as output. Pesticide amount lost to groundwater was calculated and the 80th percentile yearly amount lost (i.e., the fourth largest of the 20 simulated yearly amounts of pesticide lost) was identified as the target output to base the indicator upon. The simulations were carried out in two steps. The simulations of the first step were used as an aid in the determination of the indicator design. These simulations were also used for deriving the parameters of the indicator in combination with complementary simulations carried out in a second simulation step.

\subsubsection{Climatic scenarios}

A climatic zoning of Europe based on eight climatic factors (Table 3 ), found to mostly affect pesticide loss by leaching and drainage, have previously been performed (Blenkinsop et al., 2008) within the FOOTPRINT project (FOOTPRINT, 2011). According to this classification, Europe is divided into a total of 16 climatic zones of which four (zone 1, 2, 6 and 11, following the numbering of Centofanti et al. (2008)) are found within France (Fig. 2). The mean values of the eight climatic factors of these four zones are presented in Table 3. The 'North Mediterranean climate' (zone 1) can be summarized as warm and with moderate precipitation. The 'Temperate maritime climate' (zone 2) also have a moderate precipitation but consist of fewer extremes. The 'Alpine climate' (zone 6) are cool and wet and characterized by relatively many extreme events. The 'Modified temperate maritime climate' (zone 11) is warm and wet but with rather relatively few wet days in the spring. Zone 6 was excluded from the indicator as a potential climatic scenario since the cultivated area in this part of France (the Alps) is negligible.

Modified climatic series of 26 years (1975-2000) obtained from weather stations that are representative of the climatic zones (Blenkinsop et al., 2008) found in France were used as driving data in the MACRO model. The modification consisted of disaggregating daily precipitation totals into hourly precipitation using a scaling cascade model (Olsson, 1998) and setting the precipitation to $0 \mathrm{~mm}$ on the day of pesticide application since spraying on a day of heavy rainfall is not in accordance with good management practices. 


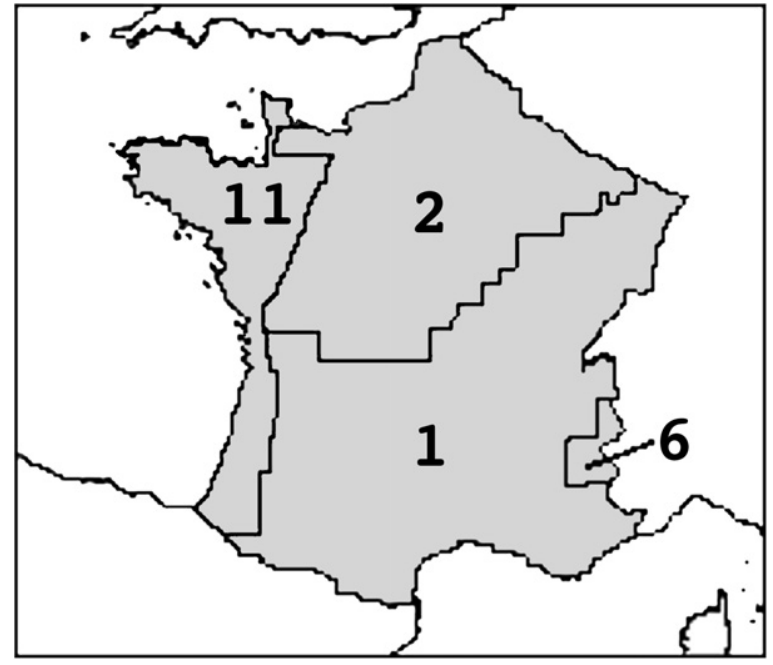

Fig. 2. The four climatic zones of France. Zone 1: 'North Mediterranean climate', zone 2: 'Temperate maritime climate', zone 6: 'Alpine climate', and zone 11: 'Modified temperate maritime climate'.

\subsubsection{Crop and pesticide application scenarios}

Two different crop scenarios were considered, winter wheat sown in autumn and maize sown in spring. These crops were selected since they are the main crops regarding sown surface area in France (Agreste, 2010). Three different seasons of pesticide application were considered, autumn application on winter wheat on the 20th of September, winter application on winter wheat on the 1 st of March and spring application on maize on the 30th of April. The combinations of climatic zones and seasons of application give a total of nine unique weather regimes.

The maximum root depth of the crops was limited to the depth of the soil profile except for subsoils of coarse texture (sand content $>65 \%$ and clay content $<18 \%$, according to CEC (1985)) for which the root penetration was considered to be limited to $45 \mathrm{~cm}$. The other MACRO crop parameters used follows those of the FOOTPRINT project (Jarvis et al., 2007) and MACRO default values.

Even though the spring applications occur post-emergence, all of the pesticide was simulated as sprayed directly on the soil, i.e., interception of canopy was not accounted for in the MACRO simulations. Instead, the pesticide dose reaching the soil surface (referred

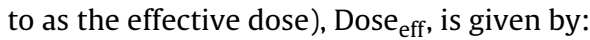

Dose $_{\mathrm{eff}}=$ Dose $_{\mathrm{appl}} \cdot F_{\mathrm{int}}$,

where Dose $\mathrm{appl}_{\mathrm{a}}$ is the pesticide dose applied on the field and $F_{\text {int }}$ is a factor corresponding to the proportion of the pesticide that actually reach the soil surface (deducting for e.g. wind drift and crop interception).

\subsubsection{Pesticide scenarios}

The leaching of seven hypothetical pesticides with different $\mathrm{DT}_{50}$ and $K_{\mathrm{oc}}$ was simulated for an effective dose of $1 \mathrm{~kg} \mathrm{ha}^{-1}$ (Table 4). The pesticides varied within a span ranging from high risk leachers (as they were both mobile $\left(K_{\mathrm{oc}}=27 \mathrm{~cm}^{3} \mathrm{~g}^{-1}\right)$ and moderately persistent in the soil $\left(\mathrm{DT}_{50}=60\right.$ days $)$ ) to low risk leachers (being slightly mobile $\left(K_{\mathrm{oc}}=600 \mathrm{~cm}^{3} \mathrm{~g}^{-1}\right)$ and non-persistent $\left(\mathrm{DT}_{50}=5\right.$ days $)$ ). Three of the pesticides were used as an aid for determining the indicator design (Table $4 a$ ), the other four were simulated as complementary pesticides for deriving the membership functions of the indicator (Table $4 \mathrm{~b}$ ).

Pesticide degradation usually decreases with depth (Boesten and van der Linden, 1991). To capture this characteristic, the degradation rate coefficients of the second and third horizons were calculated by multiplying the corresponding parameter value for
Table 4

Properties of (a) the pesticides simulated for determining the indicator design, (b) the complementary pesticides simulated. ${ }^{a}$

\begin{tabular}{lcc}
\hline a) & \\
\hline Pesticide variant & $\mathrm{DT}_{50}$ (days) & $K_{\mathrm{oc}}$-value $\left(\mathrm{cm}^{3} \mathrm{~g}^{-1}\right)$ \\
\hline A & 5 & 300 \\
B & 30 & 130 \\
C & 30 & 600 \\
& & \\
b) & & \\
\hline Pesticide variant & $\mathrm{DT}_{50}$ (days) & $K_{\mathrm{oc}}$-value $\left(\mathrm{cm}^{3} \mathrm{~g}^{-1}\right)$ \\
\hline D & 5 & 27 \\
E & 5 & 600 \\
F & 60 & 27 \\
G & 60 & 600 \\
\hline
\end{tabular}

a Abbreviations as in Table 1.

Table 5

Textural composition of soils selected to represent soils of different texture type.

\begin{tabular}{llrlc} 
Texture type & Texture class & Clay content (\%) & Silt content (\%) & $\begin{array}{l}\text { Sand } \\
\text { content (\%) }\end{array}$ \\
\hline Fine & Silty clay & 45 & 50 & 5 \\
Medium & Loam & 25 & 40 & 35 \\
Coarse & Loamy sand & 5 & 15 & 80
\end{tabular}

the first horizon with the factor 0.5 and 0.3 , respectively. These factors, based on a literature review, are used in leaching assessments for pesticide registration in the EU (FOCUS, 2000).

The sorption was modeled as instantaneous linear and the sorption coefficient was obtained by multiplying $K_{\mathrm{oc}}\left(\mathrm{cm}^{3} \mathrm{~g}^{-1}\right)$ with the organic carbon content. The rationale for adopting a simulation setup assuming linear sorption and degradation is that variations in pesticide dose can easily be accounted for by scaling the leaching predicted at a dose of $1 \mathrm{~kg} \mathrm{ha}^{-1}$. Given the relationships between indicator scores and pesticide loss in Table 2 and the linear relation between pesticide loss and application rate, indicator scores $\left(I_{\mathrm{eff}}\right)$ for any Dose $_{\text {eff }}$ is calculated as:

For $10^{y} \leq$ Dose $_{\mathrm{eff}}<10^{(y+1)} \mathrm{kg} \mathrm{ha}^{-1}$, where $y$ is an integer,

if $y \geq 0$ (i.e., Dose $_{\mathrm{eff}} \geq 1 \mathrm{~kg} \mathrm{ha}^{-1}$ )

$I_{\text {eff }}=\operatorname{MAX}\left[I_{\text {base }}-2 \cdot\left(y+\frac{\text { Dose }_{\text {eff }} \cdot 10^{-y}-1}{9}\right) ; 0\right]$

if $y \leq-1$ (i.e., Dose $_{\text {eff }}<1 \mathrm{~kg} \mathrm{ha}^{-1}$ )

$I_{\mathrm{eff}}=\operatorname{MIN}\left[I_{\text {base }}-2 \cdot\left(y+\frac{\text { Dose }_{\mathrm{eff}} \cdot 10^{-y}-1}{9}\right) ; 10\right]$

where $I_{\text {base }}$, is the output of the fuzzy inference system (i.e., the indicator score obtained for an effective pesticide dose of $1 \mathrm{~kg} \mathrm{ha}^{-1}$ ) calculated according to indicator equation (1) given in Section 2.1.2 above.

\subsubsection{Soil scenarios}

Three different textural compositions of clay, silt and sand contents (Table 5) were selected to represent soil types of fine, medium and coarse texture (for definition, see Table 6). These choices were

Table 6

Classification of soils of different texture type.

\begin{tabular}{ll}
\hline Texture type & Texture (USDA) \\
\hline Fine & Clay, clay loam, silty clay and silty clay loam \\
Medium & $\begin{array}{l}\text { Sandy clay, sandy clay loam, loam, sandy loam, silt and } \\
\text { silt loam }\end{array}$ \\
Coarse & Loamy sand, sand \\
\hline
\end{tabular}




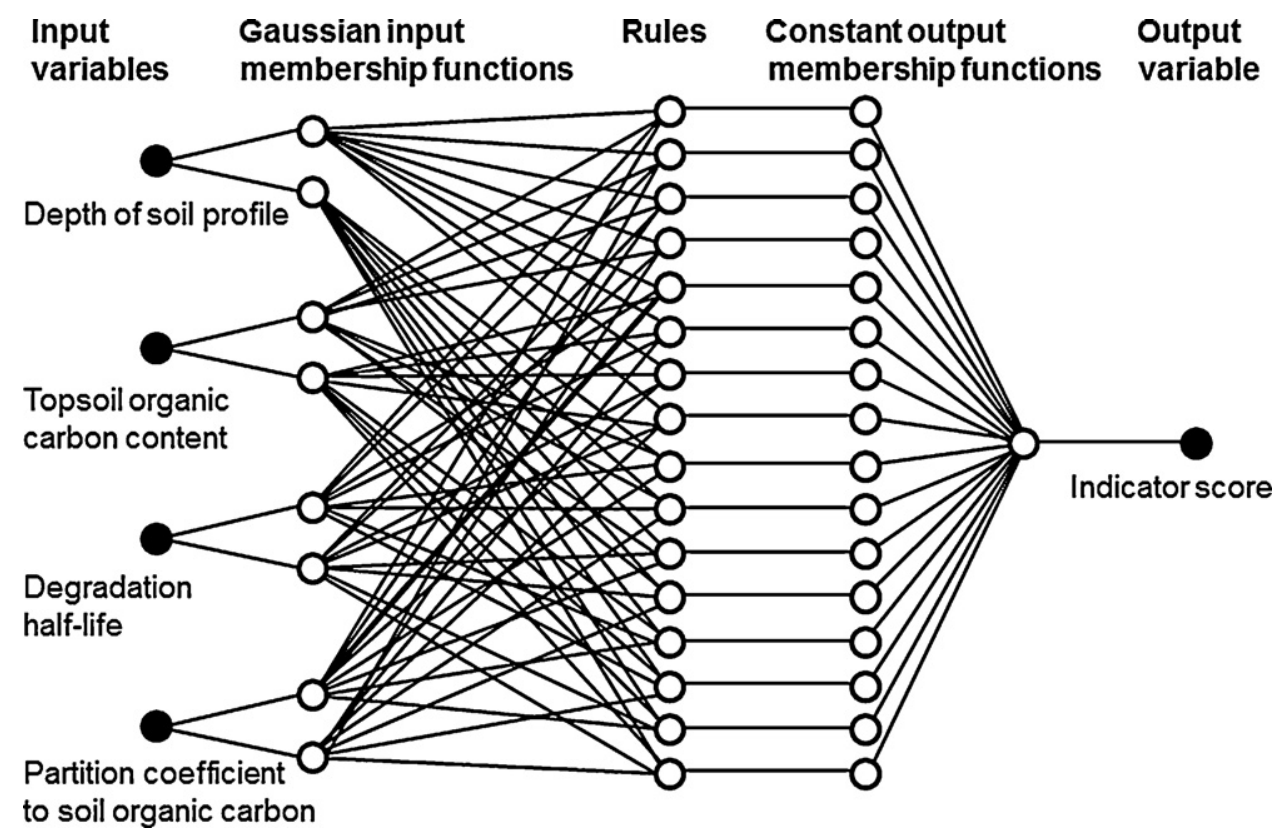

Fig. 3. Model structure of the indicator inference systems.

based on a pre-study of MACRO simulations of one representative soil from each of the 12 USDA textural classes (USDA, 2011) (results not shown here). For fine textured soils, the silty clay gave the most pesticide leaching and was therefore chosen to represent these types of soils. Among the medium textured soils, the loam and the sandy clay were found to be the most sensitive to the degree of susceptibility to preferential flow and are thereby also potentially sensitive to tillage operations (see Appendix A). Of these two soils the loam was selected to represent soils of medium texture. Even though the sandy soil gave the highest pesticide leaching, the loamy sand was chosen to represent coarse textured soils since it is uncommon that sandy soils are cultivated for arable crops.

In the first simulation step, the MACRO model was parameterized for soil profiles of either $40 \mathrm{~cm}$ or $100 \mathrm{~cm}$ depth. The soil profiles were divided into two or three horizons $(0-30 \mathrm{~cm}$, $30-60 \mathrm{~cm}$ and $60-100 \mathrm{~cm}$ ). The second and third horizons (jointly referred to as the subsoil) of each soil profile were always assigned the same textural composition while the textural composition of the first horizon (referred to as the topsoil) could differ from that of the subsoil. All in all, nine textural combinations were simulated. For the topsoils, an organic carbon content of $1 \%$ and $3 \%$ were simulated, whereas the organic carbon content in the subsoils was fixed to $0.5 \%$. These values were also used in the second simulation step, supplemented with soil scenarios having topsoil organic carbon contents of $2 \%$ and soil depths of $70 \mathrm{~cm}$.

It is common that sandy soils contain a rather high percentage of stones and consequently contain less active soil material for degradation and adsorption. As an effect, such soils have a potential to leach more than a comparable soil without stones. In a pre-study, the leaching of the pesticides defined in Table 4a were therefore also simulated for soil profiles of coarse textured topsoil with a stone content of $10 \%$, overlaying either coarse textured subsoil containing the same stone content, or medium or fine textured subsoil without stones.

\subsection{Comparison of the new and the old indicator}

A comparison of the new and old groundwater indicator module was conducted. The comparison was carried out for two different soils, a shallow, fine textured soil and a deep, medium textured soil, located in climate zone 1 . The organic carbon content is $2 \%$ for both soils. The comparison comprises the two crops, maize and winter wheat. Two maize herbicides were applied in spring and one wheat herbicide was compared for autumn or winter application. Additionally, glyphosate was compared on maize in spring and on winter wheat in autumn. Data on pesticide characteristics were derived from the database used for the I-Phy indicator (non-published). This database is based on a compilation between the French database for registration AGRITOX (2011), and other sources (e.g. Tomlin, 2009). Two different doses were used for each pesticide. These doses are in line with those recommended by the manufacturers and consistent with levels implemented by farmers.

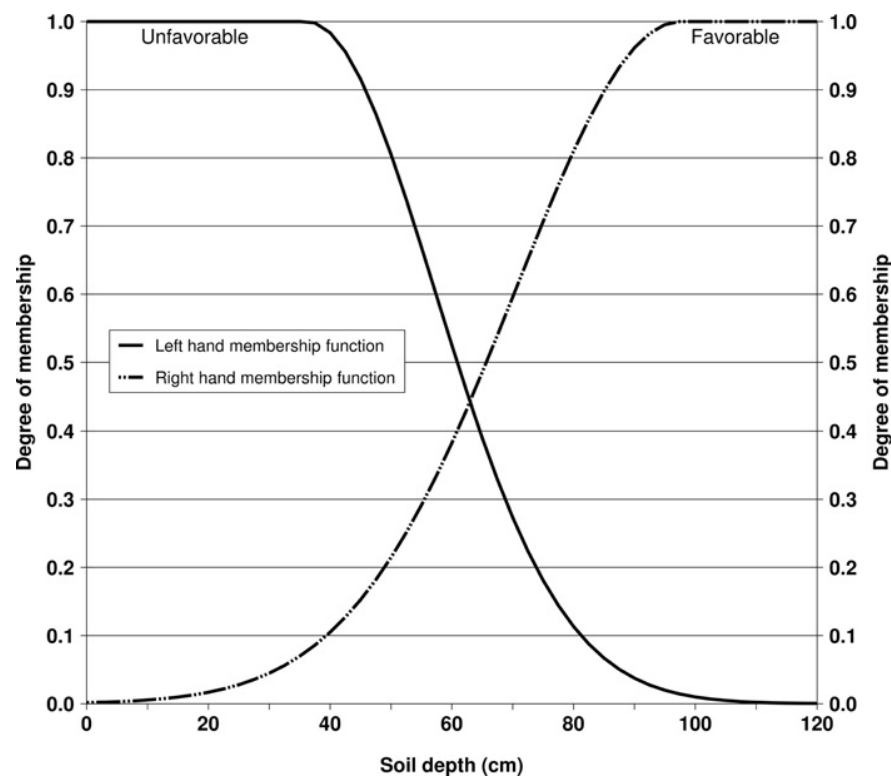

Fig. 4. Input membership function plot for soil profile depth $(\mathrm{cm})$ for an autumn applied, medium textured soil profile, located in climate zone 1. 


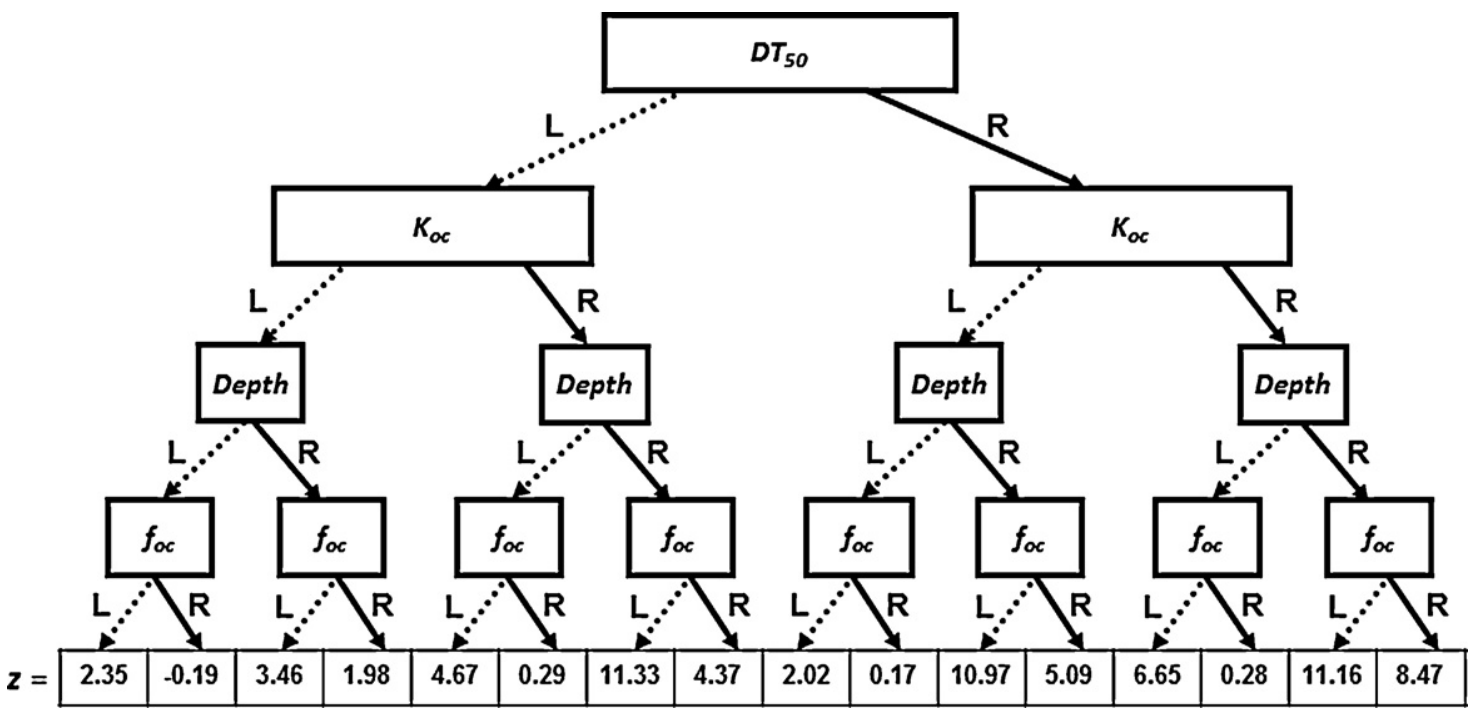

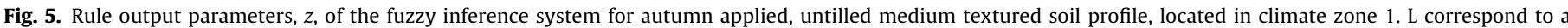

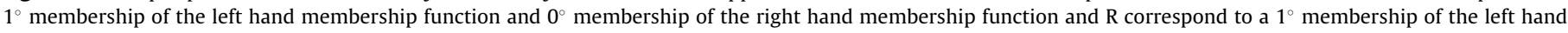
membership function and $0^{\circ}$ membership of the right hand membership function. Abbreviations as in Table 1 .

\section{Results}

\subsection{Decision tree variable selection}

According to the pre-study, pesticide leaching was only slightly affected by stone content in coarse textured topsoil and tillage practice on fine textured topsoil. For stoniness, the divergence in pesticide leaching risk between soils with no stone content and soils with a stone content of $10 \%$ exceeded 0.5 indicator score units for 14 out of 324 pairs of comparison cases ( 3 pesticide variants, 9 weather regimes, 3 subsoil textures, 2 soil depths and 2 topsoil organic carbon contents). The average and maximum divergence were 0.1 and 1.2 indicator score units, respectively. The corresponding values for the different tillage systems on fine textured soil were nine out of 324 pairs of comparison cases ( 3 pesticide variants, 9 weather regimes, 3 subsoil textures, 2 soil depths and 2 topsoil organic carbon contents) diverging more than 0.5 indicator score units, with an average and maximum divergence of 0.1 and 1.4 indicator score units, respectively. These differences were judged not to be significant enough to justify their inclusion in the indicator design. Stoniness in coarse textured soils and the ploughed option for fine textured soils were therefore excluded from the indicator design at an early stage of the developing process. The number of MACRO simulations needed was thereby reduced. Combining the nine textural scenarios (i.e., all the texture combinations of topsoil and subsoil possible) with the two options of tillage for soil profiles having a medium textured topsoil and the nine weather regimes considered give a total of 108 discrete scenarios.

\subsection{Fuzzy inference systems}

All the predefined types of membership functions and weight functions available in the MATLAB Fuzzy Logic Toolbox were considered. For each discrete scenario, the data learning set comprised 44 unique combinations of input variables and their associated indicator scores. The learning process was carried out until no further improvement was achieved or until a maximum of 100,000 adjustments had been carried out. A sufficient fit between data sets and inference systems was defined as a maximum root mean square error of 0.5 indicator scores. All fuzzy inference systems derived fulfilled this requirement with regard to their associated data learning sets. The structure of the inference systems derived is presented in Fig. 3.

The smallest errors were achieved for Gaussian membership functions (e.g., see Fig. 4) with backpropagation algorithm in combination with a least square type of model as optimization method. The performance (assessed by rmse) of fuzzy inferences systems with weights calculated as the product (prod) or the minimum of variables degree of membership to the relevant fuzzy set were compared. The prod weighting function performed best and was therefore selected to be the indicator method of weighting.

The Gaussian membership function depends on a variable, $x$, (e.g. soil depth as in Fig. 4) and two parameters, $c$ and $\sigma$, as given by

$f_{\mathrm{mb}}(x)=e^{\left(-\left(g_{\mathrm{mb}}(x)-c_{\mathrm{mb}}\right)^{2} /\left(2 \cdot \sigma_{\mathrm{mb}}^{2}\right)\right)}$

where $\mathrm{mb}=L$ for the left hand membership function and $\mathrm{mb}=R$ for the right hand membership function and

$g_{\mathrm{L}}(x)=\max \left(c_{\mathrm{L}}, x\right)$

and

$g_{\mathrm{R}}(x)=\max \left(c_{\mathrm{R}}, x\right)$.

Rules were derived for the 16 possible combinations of favorable and unfavorable membership for the four continuous variables considered. Due to constraints in the available number of simulations (44) for each discrete scenario, constant output membership functions were chosen for each rule in favor of the more data demanding linear option. Each of the fuzzy inference systems constructed comprise 32 parameters. The indicator developed is organized in such a way that each fuzzy inference system is represented by a table containing 16 membership function parameters and a tree of which each path makes up one rule, giving a total of 16 rule output parameters (e.g., see Table 7 and Fig. 5). From these data, indicator scores (for any dosage) can be calculated using the six indicator equations given above.

\subsection{Indicator finalization through pruning}

The MACRO output data sets were compared to inference systems for which the subsoil diverged from that of the data set. For soil profiles with fine textured topsoil the simulated leaching result was 
Table 7

The membership function parameter set of the fuzzy inference system for autumn applied, medium textured soil profile, located in climate zone $1 .^{\text {a }}$

\begin{tabular}{|c|c|c|c|c|c|}
\hline Variable number & Variable name & $c_{\mathrm{L}}$ & $\sigma_{\mathrm{L}}$ & $c_{R}$ & $\sigma_{\mathrm{R}}$ \\
\hline 1 & Topsoil organic carbon content (\%) & 0.809 & 0.684 & 2.87 & 0.929 \\
\hline 2 & Depth of soil profile (cm) & 36.2 & 21.0 & 97.6 & 27.1 \\
\hline 3 & $K_{\mathrm{oc}}\left(\mathrm{cm}^{3} \mathrm{~g}^{-1}\right)$ & 27.1 & 243 & 600 & 243 \\
\hline 4 & $\mathrm{DT}_{50}$ (days) & 1.89 & 20.3 & 57.7 & 25.2 \\
\hline
\end{tabular}

a Abbreviations as in Table 1.

sensitive to subsoil texture (Fig. 6) especially for autumn application. For climate zone 2, the data sets for soil profiles with medium textured topsoil and subsoil fitted the fuzzy inference systems of the corresponding data set having a coarse subsoil, even in case of a diverging tillage options (rmse $\leq 0.3$ indicator scores) (e.g., see Fig. 7).

Each MACRO output data sets of soil profiles with ploughed medium textured topsoil was compared to the fuzzy inference systems derived for the corresponding untilled scenarios. The root mean square derivations did not exceed our pruning criterion of 0.5 indicator scores. The variable concerning tillage was therefore completely excluded from the indicator.

For soil profiles with coarse textured topsoil, indicator scores for medium textured subsoil fitted the fuzzy inference system developed (rmse $\leq 0.5$ indicator scores) from the data set for coarse textured subsoil for all climate and application scenarios (data not shown). A sufficiently good match was also achieved for fine textured subsoils except for winter application in climate zone 1 (rmse $=0.7$ indicator scores) and spring application in climate zone 11 (rmse $=0.6$ indicator scores) (data not shown). The size of the indicator could therefore be decreased to 62 unique fuzzy inference systems to choose from depending on the prevailing situation regarding soil texture, climatic zone and season of application.

Comparisons of simulated pesticide leaching risk for different climatic zones showed that zone 2 and 11 differ the most (average rmse of 1.3 indicator scores), especially for autumn application (average rmse of 1.8 indicator scores). The largest resemblance is found for climate zone 1 and 11 (average rmse of 0.9 indicator scores), especially for spring applied pesticide (average rmse of 0.6 indicator scores). Similar comparison for different application

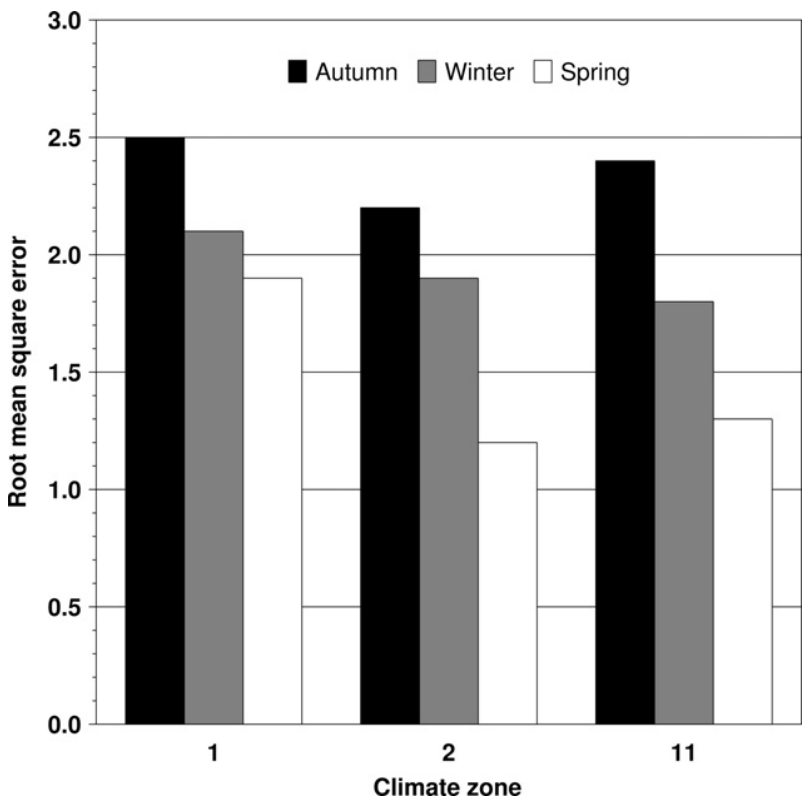

Fig. 6. Root mean square error for data learning sets of soils having a fine topsoil and subsoil when applied for fuzzy inference systems based on data learning sets of soils having a fine topsoil and a coarse subsoil for different application seasons. seasons showed that most resemblance in leaching risk was found for spring and winter application (average rmse of 0.6 indicator scores). The largest difference was found for autumn and spring application (average rmse of 1.7 indicator scores), especially for climate zone 11 (average rmse of 2.1 indicator scores). To retain a good indicator structure (i.e., avoiding numerous special cases), no fuzzy inference system was excluded from the indicator due to matches found between different seasons of application or climates.

\subsection{Variable sensitivity}

The climatic statistics are more favorable for zone 2 than for the other climatic zones (Table 3 ). This characteristic was also expressed by the indicator, for which climate zone 2 generally produce the lowest pesticide leaching risk (for example on the effect of climate on indicator scores, see Table 8a).

According to the results, autumn application generally presents a higher risk of pesticide leaching than winter or spring application (for example on the effect of season of application on indicator scores, see Table 8b). This is presumably due to the more frequent events of high daily precipitation amount during the autumn (Table 3).

The indicator developed is sensitive to preferential flow. It captures the characteristics of preferential flow as being strongest in fine textured soils and most effective in topsoils (for example on the effect of soil texture on indicator scores, see Table 8c). Therefore, there is a risk for large losses for soils prone to preferential flow under climatic conditions that trigger such flows even for pesticides having a very low GUS-index (e.g. 0.85 for a pesticide with a $\mathrm{DT}_{50}$ of 5 days and a $K_{\mathrm{oc}}$ of $600 \mathrm{~cm}^{3} \mathrm{~g}^{-1}$ ). A fast flow through the soil matrix, such as in the case of coarse textured soils, can also cause a

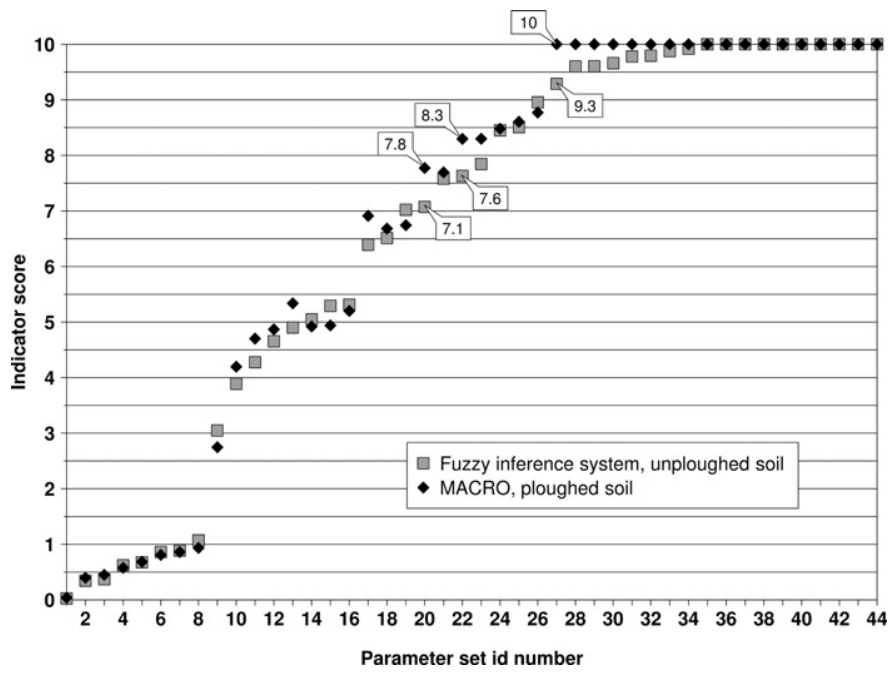

Fig. 7. Indicator score calculated for MACRO outputs (black diamonds) for autumn application in climate zone 2 on a ploughed medium textured soil profile and the result for the fuzzy inference system (gray squares) for a untilled soil profile with a medium textured topsoil and a coarse textured subsoil for the same climate and season of application. The rmse of the values of the data set and the resulting values of the fuzzy inference system is 0.2 indicator scores. 
Table 8

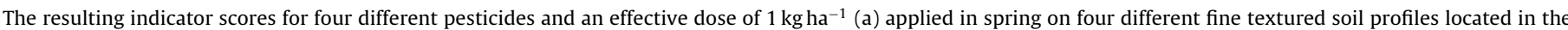

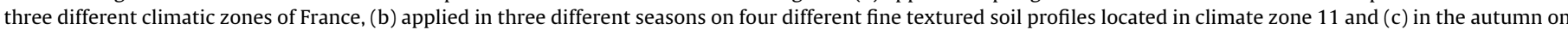
112 soil profiles of different texture, organic carbon content and soil depth located in climate zone $1 .^{\mathrm{a}}$

\begin{tabular}{|c|c|c|c|c|c|c|}
\hline \multicolumn{4}{|c|}{ Continuous input variables } & \multicolumn{3}{|c|}{ Climatic zone } \\
\hline $\mathrm{DT}_{50}$ (days) & $K_{\mathrm{oc}}$-value $\left(\mathrm{cm}^{3} \mathrm{~g}^{-1}\right)$ & Soil depth $(\mathrm{cm})$ & Organic carbon content (\%) & 1 & 2 & 11 \\
\hline \multirow[t]{8}{*}{60} & 27 & 40 & 1 & 1 & 1 & 1 \\
\hline & & & 3 & 1 & 1 & 1 \\
\hline & & 100 & 1 & 2 & 2 & 1 \\
\hline & & & 3 & 2 & 3 & 2 \\
\hline & 600 & 40 & 1 & 2 & 2 & 2 \\
\hline & & & 3 & 3 & 3 & 2 \\
\hline & & 100 & 1 & 2 & 3 & 2 \\
\hline & & & 3 & 3 & 5 & 3 \\
\hline \multirow[t]{8}{*}{5} & 27 & 40 & 1 & 4 & 6 & 4 \\
\hline & & & 3 & 5 & 9 & 7 \\
\hline & & 100 & 1 & 5 & 9 & 6 \\
\hline & & & 3 & 6 & 10 & 10 \\
\hline & 600 & 40 & 1 & 6 & 10 & 9 \\
\hline & & & 3 & 10 & 10 & 10 \\
\hline & & 100 & 1 & 10 & 10 & 10 \\
\hline & & & 3 & 10 & 10 & 10 \\
\hline
\end{tabular}

b)

\begin{tabular}{|c|c|c|c|c|c|c|}
\hline \multicolumn{4}{|c|}{ Continuous input variables } & \multicolumn{3}{|l|}{ Season } \\
\hline $\mathrm{DT}_{50}$ (days) & $K_{\mathrm{oc}}$-value $\left(\mathrm{cm}^{3} \mathrm{~g}^{-1}\right)$ & Soil depth $(\mathrm{cm})$ & Organic carbon content (\%) & Autumn & Winter & Spring \\
\hline \multirow[t]{8}{*}{60} & 27 & 40 & 1 & 0 & 1 & 1 \\
\hline & & & 3 & 0 & 1 & 1 \\
\hline & & 100 & 1 & 1 & 1 & 1 \\
\hline & & & 3 & 1 & 1 & 2 \\
\hline & 600 & 40 & 1 & 1 & 2 & 2 \\
\hline & & & 3 & 1 & 3 & 2 \\
\hline & & 100 & 1 & 1 & 2 & 2 \\
\hline & & & 3 & 1 & 3 & 3 \\
\hline \multirow[t]{8}{*}{5} & 27 & 40 & 1 & 2 & 1 & 4 \\
\hline & & & 3 & 2 & 2 & 7 \\
\hline & & 100 & 1 & 2 & 1 & 6 \\
\hline & & & 3 & 3 & 3 & 10 \\
\hline & 600 & 40 & 1 & 2 & 6 & 9 \\
\hline & & & 3 & 4 & 10 & 10 \\
\hline & & 100 & 1 & 3 & 9 & 10 \\
\hline & & & 3 & 5 & 10 & 10 \\
\hline
\end{tabular}

c)

\begin{tabular}{|c|c|c|c|c|c|c|c|c|c|c|}
\hline \multicolumn{4}{|c|}{ Continuous input variables } & \multicolumn{7}{|c|}{ Topsoil texture subsoil texture } \\
\hline $\mathrm{DT}_{50}$ (days) & $K_{\mathrm{oc}}$-value $\left(\mathrm{cm}^{3} \mathrm{~g}^{-1}\right)$ & Soil depth $(\mathrm{cm})$ & Organic carbon content (\%) & $\mathrm{C}^{\mathrm{b}}$ All & $\mathrm{M}^{\mathrm{c}} \mathrm{C}$ & M M & $M F^{d}$ & FC & F M & F F \\
\hline \multirow[t]{8}{*}{60} & 27 & 40 & 1 & 0 & 0 & 0 & 0 & 0 & 0 & 0 \\
\hline & & & 3 & 0 & 0 & 1 & 1 & 0 & 0 & 1 \\
\hline & & 100 & 1 & 0 & 0 & 1 & 1 & 1 & 1 & 1 \\
\hline & & & 3 & 1 & 1 & 1 & 1 & 1 & 1 & 1 \\
\hline & 600 & 40 & 1 & 5 & 3 & 2 & 2 & 2 & 1 & 1 \\
\hline & & & 3 & 8 & 6 & 5 & 4 & 2 & 2 & 1 \\
\hline & & 100 & 1 & 9 & 7 & 5 & 2 & 5 & 3 & 1 \\
\hline & & & 3 & 10 & 10 & 8 & 6 & 7 & 4 & 2 \\
\hline \multirow[t]{8}{*}{5} & 27 & 40 & 1 & 2 & 2 & 2 & 2 & 2 & 2 & 1 \\
\hline & & & 3 & 4 & 3 & 3 & 3 & 2 & 2 & 2 \\
\hline & & 100 & 1 & 4 & 5 & 5 & 3 & 5 & 4 & 2 \\
\hline & & & 3 & 6 & 6 & 6 & 4 & 5 & 4 & 3 \\
\hline & 600 & 40 & 1 & 10 & 7 & 5 & 4 & 5 & 3 & 3 \\
\hline & & & 3 & 10 & 10 & 10 & 9 & 7 & 5 & 5 \\
\hline & & 100 & 1 & 10 & 10 & 10 & 6 & 10 & 7 & 4 \\
\hline & & & 3 & 10 & 10 & 10 & 10 & 10 & 10 & 7 \\
\hline
\end{tabular}

Shaded scores are judged to indicate unacceptable pesticide leaching risks.

a Abbreviations as in Table 1.

b Coarse.

c Medium.

d Fine. 
high risk for pesticide leaching, especially for mobile pesticides in shallow soils.

Regarding the continuous variables, the indicator is more sensitive to pesticide characteristics than soil properties (for example, see Table $8 a-c)$.

\subsection{Comparison of the new and the old indicator}

A comparison of the new groundwater indicator and the former one shows that the new indicator is more sensitive to soil conditions (Table 9). Due to the low GUS-index of glyphosate (GUS-index $=1.5$ ), the old indicator classifies the risk for high concentrations of this pesticide in the groundwater as very low. On the contrary, by including the processes of preferential flow, the new indicator classifies the risk of glyphosate losses to groundwater as high to very high for unfavorable soil conditions. This result is supported by previous studies performed at field and lysimeter scales (Vereecken, 2005; Kjaer et al., 2005). Additionally, since the new indicator takes the influence of weather patterns into account (affected by the variables climatic zone and, as in this comparison, the application season), the difference in contamination risk becomes larger between seasons in comparison to the risk according to the old indicator. For the old indicator, the differences in risk between application seasons (see indicator scores for isoproturon for winter and autumn application in Table 9) are simply due to changes in the effective dose caused by difference in crop development.

\section{Discussion}

The main improvement of the new indicator developed is a reduced dependency on the expert knowledge of the designers. The implementation of the MACRO model enabled us to explore a broader range of situations of pesticide leaching than what is available in the literature on experimental data about the effect of different factors. Furthermore, this method allowed for an inclusion of non-linear processes of which some are interlinked and thereby impossible to predict sufficiently enough by experts. Another improvement of the indicator is that, in comparison to the old version the new indicator takes more variables into account and considers environmental parameter sets on climate and soil structure.

Water is the dominant transport medium of pesticides in soil. Consequently, precipitation pattern following application is a very important factor governing pesticide losses. Also of importance is the soil water content at the time of application, especially if the soil is prone to preferential flow (Jarvis, 2007). Pesticide leaching is thus governed by both previous and current climate conditions. Their interactions are still poorly understood and the effects of precipitation intensity and duration on pesticide leaching depend also on soil properties and pesticide characteristics (McGrath et al., 2008; Nolan et al., 2008). MACRO simulation studies have been performed to identify key climatic factors governing the transport of pesticide leaching (Lewan et al., 2009; Blenkinsop et al., 2008; Nolan et al., 2008). Many of the relevant factors are associated with rainfall events in a far future. Such factors cannot be predicted and are therefore unfitting as indicator variables unless supplemented with site specific factors of risk (e.g. reflecting the risk of exceeding certain rainfall amounts during the winter months). Additionally, to include all the significant climatic factors for specific soil-pesticide combinations as separate indicator parameters would result in a very complex decision tree. Instead, precipitation pattern and soil water content at the time of application are implicitly taken into account by the indicator. This was achieved through basing the indicator on the 80th percentile yearly amount pesticide lost calculated from MACRO simulations of 20 years of weather data for each French climatic zone (based on the eight significant climatic factors identified by Blenkinsop et al. (2008)) and application season considered (i.e., spring, autumn and winter), Consequently, the indicator take the overall risk of both previous and current climate conditions into account for each combination of climatic zone and application season.

The previous version of the indicator did not account for differences in texture with depth. For the new indicator, subsoil texture can significantly affect the resulting score. For example the pesticide leaching from soils with fine textured topsoil is very sensitive to subsoil texture regardless the climatic zone or application season. Soil data are thus more explicitly introduced in this new version. The former version includes a variable reflecting the overall soil leaching potential instead. This variable is assessed either in a separate decision tree (Bockstaller, 2004) or by expertise in the field (e.g. according to the method of Réal (2004)). In a comparison, the assessment by means of the decision tree has been found to be weakly related to field assessment of leaching risk (Novak et al., 2009). The advantage of allowing for integration of field assessments is not available in the new version.

Preferential flow is taken into account by the indicator through its link to the MACRO model. Since the previous version ignores this process, it considers fine textured soils to present a smaller risk of pesticide leaching than coarse textured soils and categorizes pesticides of low GUS-index as non-leachers. On the contrary, the new indicator shows that fine textured soils may present a higher risk for pesticides losses to the groundwater compared to coarse textured soils. Additionally, due to the influence of preferential flow, the new indicator does not rely on the GUS-index for estimating the pesticide leachability but takes both the pesticide characteristics $\mathrm{DT}_{50}$ and $K_{\mathrm{oc}}$ into consideration separately. In the old version, pesticide dose was not considered by the groundwater module itself, but was dealt with in a separate module. The dose is now more explicitly integrated, in quantitative interaction with interception, taking into account the assumption of linear sorption and degradation.

Neither the old nor the new version allows for any manipulation of tillage by the end user. For the new indicator, an option of tillage/no tillage was tested as a potential input variable. But, as a consequence of the transformation of pesticide loss into indicator score (a $\log _{10}$ change in pesticide loss correspond to a change of two indicator score units) tillage implements did not significantly affect the resulting output. The tillage/no tillage option could thus be pruned away. Field studies (Alletto et al., 2010) have shown that suppression of ploughing can increase leaching by a factor of $60 \%$ in average $(N=21$, a total of 11 different pesticides reviewed in nine studies). Hence, one can expect a positive effect of tillage on pesticide loss to groundwater but it is not a significant factor when assessing the risk of pesticide leaching in a worst-case scenario.

The new indicator is applicable for 62 scenarios comprising a broad range of conditions. For each of these scenarios, the structure of the decision tree is the same (see Fig. 5) but the shape of their membership functions (determined by their membership function parameter set) and their set of rule output parameters are unique. The structure of the new indicator is thereby more complex than the former indicator which consists of a single set of membership function parameters and rule output parameters. By grouping the scenarios into nine schemes according to climatic zone and application season, the indicator becomes easier to handle when looking up which parameter set to choose for a particular situation of pesticide application. It is also possible to reduce the number of scenarios by some additional pruning of climatic zones in combination with application seasons. This would however not facilitate the use of the indicator since these two variables should always be known to the 
Table 9

Comparison of results of the new and the old indicator for different pesticide application systems on two different soils in northern France.

\begin{tabular}{|c|c|c|c|c|c|c|c|}
\hline Crop & Active ingredient & Season & Texture & Soil depth & Dose $\left(\mathrm{g} \mathrm{ha}^{-1}\right)$ & $\begin{array}{l}\text { New indicator } \\
\text { score }\end{array}$ & $\begin{array}{l}\text { Old indicator } \\
\text { score }\end{array}$ \\
\hline \multirow[t]{4}{*}{ Maize } & \multirow[t]{4}{*}{ S-metolachlor } & \multirow[t]{4}{*}{ Spring } & \multirow[t]{2}{*}{ Fine } & \multirow[t]{2}{*}{ Shallow $(40 \mathrm{~cm})$} & 1900 & 3.4 & 4.2 \\
\hline & & & & & 950 & 3.7 & 4.9 \\
\hline & & & \multirow[t]{2}{*}{ Medium } & \multirow[t]{2}{*}{ Deep $(100 \mathrm{~cm})$} & 1900 & 7.2 & 6.3 \\
\hline & & & & & 950 & 7.5 & 6.7 \\
\hline \multirow[t]{4}{*}{ Maize } & \multirow[t]{4}{*}{ Mesotrione } & \multirow[t]{4}{*}{ Spring } & \multirow[t]{2}{*}{ Fine } & \multirow[t]{2}{*}{ Shallow $(40 \mathrm{~cm})$} & 100 & 7.0 & 9.8 \\
\hline & & & & & 50 & 8.1 & 9.9 \\
\hline & & & \multirow[t]{2}{*}{ Medium } & \multirow[t]{2}{*}{ Deep $(100 \mathrm{~cm})$} & 100 & 10.0 & 9.8 \\
\hline & & & & & 50 & 10.0 & 9.9 \\
\hline \multirow{4}{*}{ Winter wheat } & \multirow[t]{4}{*}{ Isoproturon } & \multirow[t]{4}{*}{ Winter } & \multirow[t]{2}{*}{ Fine } & \multirow[t]{2}{*}{ Shallow $(40 \mathrm{~cm})$} & 1000 & 2.7 & 6.4 \\
\hline & & & & & 500 & 3.8 & 6.9 \\
\hline & & & \multirow[t]{2}{*}{ Medium } & \multirow[t]{2}{*}{ Deep $(100 \mathrm{~cm})$} & 1000 & 7.6 & 7.6 \\
\hline & & & & & 500 & 8.7 & 7.8 \\
\hline \multirow[t]{4}{*}{ Winter wheat } & \multirow[t]{4}{*}{ Isoproturon } & \multirow[t]{4}{*}{ Autumn } & \multirow[t]{2}{*}{ Fine } & \multirow[t]{2}{*}{ Shallow $(40 \mathrm{~cm})$} & 1000 & 1.0 & 5.3 \\
\hline & & & & & 500 & 2.2 & 6.0 \\
\hline & & & \multirow[t]{2}{*}{ Medium } & \multirow[t]{2}{*}{ Deep $(100 \mathrm{~cm})$} & 1000 & 4.7 & 6.9 \\
\hline & & & & & 500 & 5.8 & 7.3 \\
\hline \multirow[t]{4}{*}{ Maize } & \multirow[t]{4}{*}{ Glyphosate } & \multirow[t]{4}{*}{ Spring } & \multirow[t]{2}{*}{ Fine } & \multirow[t]{2}{*}{ Shallow $(40 \mathrm{~cm})$} & 2000 & 3.6 & 9.0 \\
\hline & & & & & 1000 & 3.8 & 9.2 \\
\hline & & & Medium & Deep $(100 \mathrm{~cm})$ & 2000 & 7.3 & 9.0 \\
\hline & & & & & 1000 & 7.5 & 9.2 \\
\hline Winter wheat & Glyphosate & Autumn & Fine & Shallow $(40 \mathrm{~cm})$ & 2000 & 1.1 & 9.0 \\
\hline & & & & & 1000 & 1.3 & 9.1 \\
\hline & & & Medium & Deep $(100 \mathrm{~cm})$ & 2000 & 8.5 & 9.0 \\
\hline & & & & & 1000 & 8.8 & 9.1 \\
\hline
\end{tabular}

Shaded scores are judged to indicate unacceptable pesticide leaching risks.

user. Thus, to avoid numerous special cases, we decided to keep all possible combinations of climatic zone and season of application.

As for the former version, the indicator consists of a number of transparent functions. The tree structure of the groundwater module is simple and thereby easy to understand and interpret. However, applying fuzzy logic for intermediate situations may produce indicator outputs that can be difficult to understand. By studying the calculations (i.e. membership functions) for the intermediate values involved, this black box effect can be overcome. Tracing the calculations of mechanistic models, like MACRO, would be more complicated.

The learning data sets only sparsely cover the MACRO model parameter space. This may result in inference systems that are over-fitted to its learning data (Babuška and Verbruggen, 2003). However, when testing the scenarios with data sets of different options of discrete variables (e.g., regarding tillage or subsoil texture) the rmse was 0.7 indicator scores at its highest. This indicates that the learning data sufficiently capture the features the indicator is trying to represent and consequently, any problems with over-training of the inference systems are of minor importance. It would be desirable to test the predictive power of the indicator for separate sets of field or laboratory data. However, it is difficult to find an appropriate data set that match the output of the indicator, i.e., the risk of an 80th percentile yearly amount pesticide lost under natural weather conditions of that of France. Field and laboratory data are often limited to much shorter time spans. Instead of seeking to find matching data sets to test for quantitative correspondence, a possible solution could be qualitative performance tests. The indicator outputs could for example be compared to data on pesticide concentrations or frequency of detection according to the probability test described in Bockstaller and Girardin (2003). Another possibility could be to test the indicator by comparing its results to that of other models as was done in the CAPER project (Reus et al., 2002). The uncertainty of the indicator remains yet to be evaluated. Estimates of indicator uncertainty are rarely provided (Bockstaller et al., 2008a). For the former version of I-Phy, Assaghir (2010) studied the influence of input variable uncertainty (mainly pesticide properties) on the indicator output.

\section{Conclusion}

We developed an indicator on the basis of simulations from a mechanistic model by means of data-mining methods according to the proposal of Bockstaller et al. (2008a). The indicator is in the form of a neuro-fuzzy system, combining the semantic transparency of rule-based fuzzy systems with the learning capability of neural networks (Babuška and Verbruggen, 2003). The input/output data sets of the MACRO model could successfully be transformed into fuzzy inference systems of Gaussian curve membership functions forming a new I-Phy indicator module for assessing the risk of pesticide losses to groundwater. The risk was calculated as the 80th percentile yearly amount pesticide lost for three different climatic zones of France. The main improvement of the indicator is a reduced dependency on expert knowledge of the designers. This improvement is due to the integration of physically based processes. The indicator will be included as a module of the I-Phy indicator for assessing the environmental impact of pesticides. The strengths of the new indicator are that its output can quickly be calculated on a spreadsheet by just a few equations and that it only requires ten easily available input parameters and yet take preferential flow into consideration. The methodology carried out in this study could be applied to improve other modules of I-Phy. Work has been carried out with the purpose of developing a surface water module (Wohlfahrt, 2008) from simulations using the dynamic and onedimensional pesticide runoff simulation model PRZM (Carsel et al., 2003). However, the shape of the membership functions was predetermined by the developers and only one climatic scenario and one year of weather data were considered. We recommend the approach presented in this article to be implemented for the I-Phy surface water module.

\section{Acknowledgments}

This study was funded by the Office national de l'eau et des milieux aquatiques (partnership ONEMA-INRA 2010). The FOOTPRINT team kindly provided us with weather data series. Thanks are due to Elisabet Lewan and Julien Moeys (Swedish University 
Table A.1

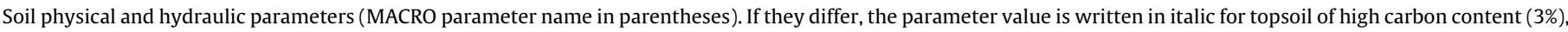
in bold for topsoil affected by ploughing and within parenthesis for soils having a stone content of $10 \%$.

\begin{tabular}{|c|c|c|c|c|}
\hline Parameter & Horizon & Fine texture & Medium texture & Coarse texture \\
\hline \multirow[t]{2}{*}{ Bulk density $\left(\mathrm{cm}^{3} \mathrm{~g}^{-1}\right)$ (GAMMA) } & $1 \mathrm{st}$ & $0.957,1.492$ & $0.957,1.492$ & $0.957,1.492$ \\
\hline & 2nd and 3rd & 1.52 & 1.52 & 1.52 \\
\hline \multirow[t]{3}{*}{ Saturated water content (\%) (TPORV) } & $1 \mathrm{st}$ & 44.61, 60.21, 46.61, 62.21 & 43.54, 59.01, 44.54, 60.01 & $40.63(37.07), 57.89(52.60)$ \\
\hline & 2nd & 42.31 & 41.28 & $39.37(35.93)$ \\
\hline & $3 r d$ & 41.51 & 40.48 & $39.37(35.93)$ \\
\hline \multirow[t]{2}{*}{ Boundary water content (\%) (XMPOR) } & $1 \mathrm{st}$ & $41.61,57.21$ & $39.54,55.01$ & $35.63(32.07), 52.89(47.60)$ \\
\hline & 2nd and 3rd & 40.71 & 39.68 & $34.37(30.93)$ \\
\hline \multirow[t]{2}{*}{ Wilting point (\%) (WILT) } & $1 \mathrm{st}$ & $23.29,26.67$ & $14.49,20.36$ & $2.95,8.85$ \\
\hline & 2nd and 3rd & 27.39 & 11.14 & 2.46 \\
\hline \multirow[t]{2}{*}{ Van Genuchten's $N(\mathrm{~N})$} & $1 \mathrm{st}$ & $1.107,1.135$ & $1.166,1.167$ & $1.302,1.387$ \\
\hline & 2nd and 3rd & 1.08 & 1.15 & 1.4 \\
\hline \multirow[t]{3}{*}{ Saturated hydraulic conductivity $\left(\mathrm{mm} \mathrm{h}^{-1}\right)$ (KSATMIN) } & $1 \mathrm{st}$ & 60.18, 100.18 & 61.05, 101.05 & 85.53 \\
\hline & 2nd & 48.18 & 49.05 & 85.53 \\
\hline & $3 r d$ & 24.18 & 25.05 & 85.53 \\
\hline \multirow[t]{2}{*}{ Boundary hydraulic conductivity $\left(\mathrm{mm} \mathrm{h}^{-1}\right)(\mathrm{KSM})$} & $1 \mathrm{st}$ & 0.18 & 1.05 & 10.53 \\
\hline & 2nd and 3rd & 0.18 & 1.05 & 10.53 \\
\hline \multirow[t]{2}{*}{ Macropore tortuosity/Pore size distribution factor (ZN) } & $1 \mathrm{st}$ & 3 & 3,4 & 4 \\
\hline & 2nd and 3rd & 2 & 2 & 4 \\
\hline \multirow{2}{*}{ Effectiv diffusion pathength (mm) (ASCALE) } & $1 \mathrm{st}$ & 50 & 15,50 & 15 \\
\hline & 2nd and 3rd & 150 & 150 & 15 \\
\hline \multirow[t]{2}{*}{ Van Genuchten's $\alpha\left(\mathrm{cm}^{-1}\right)$ (ALPHA) } & $1 \mathrm{st}$ & $0.015305,0.017772$ & $0.032806,0.033849$ & $0.028295,0.053626$ \\
\hline & 2nd and 3rd & 0.01531 & 0.03381 & 0.06340 \\
\hline
\end{tabular}

of Agricultural Sciences, Dept. Soil and Environment) for valuable discussions.

\section{Appendix A. Soil physical and hydraulic parameters}

The bottom boundary condition was set to unit hydraulic gradient indicating that the groundwater table is located at such depth that it does not affect the simulated soil profile. Soil physical and hydraulic parameters (Table A.1) were derived using pedotransfer functions, reasonable worst-case assumptions, and default values. Applying the pedotransfer function for European soils described by Wösten et al. (1998), the van Genuchten water retention parameters $\left(N, \alpha, \theta_{s}\right)$ could be determined using the input variables clay and sand contents, organic carbon content and bulk density. In MACRO, the calculated values of $\theta_{s}$ represent the porosity of the micropore domain defined by the pores draining at a fixed water potential. This boundary water potential between the macropore and micropore domain was set to $\leq-10 \mathrm{~cm}$.

The effective diffusion pathlength controlling mass exchange between the two pore domains, the exponent in the kinematic wave equation and the total saturated hydraulic conductivity were parameterized following the suggestions by Jarvis et al. (2007). This parameterization requires information of the soil macropore flow class, which can be estimated according to the predictive scheme developed by Jarvis et al. (in press). The macropore flow classes range from 'no-potential' (I) to 'high potential' (V). Tillage operations affect the soil structure and thereby the macropore flow class. If the soil is left undisturbed the tilled soil layer will re-establish due to subsequent biological activities and physical processes (Jarvis, 2007). For secondary tillage, this recovery of the soil structure was regarded to be too rapid to be considered by the indicator. Primary tillage, on the other hand, was included as a potential input variable since it is assumed that the time required for soil structure re-establishment is longer than that of the time-span of yearly ploughing.

According to the predictive scheme, coarse textured soils are either classed as macropore flow class I or II. A pre-study showed that, given the climatic conditions used in this study, the same leaching was produced disregarding the macropore flow class chosen. Coarse textured soils were therefore parameterized as belonging to macropore flow class II. The classification of medium textured topsoils varies with tillage. If the soil is ploughed, it is classified as class II, but if it is un-ploughed and trafficked it is classified as class III. A medium textured subsoil can belong to either one of the classes II, III or IV depending on the abundance of large biopores and if it is compacted or not (Jarvis et al., in press). Lindahl et al. (2009) have developed a predictive scheme for classifying the abundance of the anecic earthworm Lumbricus terrestris in agricultural soils. Combining this earthworm classification scheme with the macropore flow classification scheme of Jarvis et al. (in press), all the following features needs to be fulfilled if a medium textured subsoils is to be categorized as class III; ploughed, not regularly applied with manure, non-compacted and containing a common number of large roots. Since a macropore flow class II for medium textured soils requires a low abundance of earthworms and this is not to be expected (Lindahl et al., 2009) all the remaining medium textured subsoils fall into class IV. For the simplicity of the indicator design, the worst-case assumption of macropore flow class IV for medium textured subsoils was applied in the parameterization of the MACRO model. According to the predictive scheme, fine textured subsoils are classified as class IV. Whereas, for the scenarios relevant for the indicator, fine textured topsoils belong to class III. For fine textured topsoils the only MACRO parameters that differ between the case of a ploughed or an un-ploughed soil, are the total porosity and the total saturated hydraulic conductivity. A pre-study was therefore carried out with the purpose of finding out whether this difference had any significant effect on pesticide leaching given the soil and climatic conditions of this study. The pesticides studied in this pre-study were those presented in Table 4a.

The total porosity was given by the sum of $\theta_{s}$ and macroporosity $\left(\varepsilon_{\mathrm{ma}}\right)$ which varied with soil texture class, horizon designation and tillage as suggested by the FOOTPRINT project (based on a literature review) (Jarvis et al., 2007), with the second horizon parameterized as an upper B horizon and the third horizon as an lower B horizon. The saturated hydraulic conductivity of the micropores, $K_{b}\left(\mathrm{~mm} \mathrm{~h}^{-1}\right)$, was estimated as (Jarvis et al., 2002):

$K_{b}=25.2 \cdot d_{g}$

where $d_{g}=e^{\sum m^{i \cdot} \ln \left(d^{i}\right)}(\mathrm{mm})$ is the characteristic particle size (Shirazi and Boersma, 1984), assuming a log-normal particle size distribution, where $m_{i}$ and $d_{i}$ are the mass fraction and the arithmetic mean diameter of particle class $i(0.001 \mathrm{~mm}$ for clay, $0.026 \mathrm{~mm}$ for silt and $1.025 \mathrm{~mm}$ for sand), respectively. 
The macropore saturated conductivity $K_{s(\mathrm{ma})}$ was estimated according to a function derived from Eq. (8) in Jarvis (2008) assuming conditions of macroporous soil:

$K_{s(\mathrm{ma})}=\frac{B \cdot \varepsilon_{\mathrm{ma}}}{n^{*}}$

where $n^{*}$ is the kinematic exponent and $B$ is a composite 'matching factor' accounting for both physical constants and the geometric irregularity of the functional macropore system. $B$ was set here to $6000 \mathrm{~mm} \mathrm{~h}^{-1}$, which is the same value used by FOOTPRINT (Jarvis et al., 2007). The total saturated hydraulic conductivity is given by the sum of the saturated hydraulic conductivities of the micropores and the macropores.

The dispersivity was set to $5 \mathrm{~cm}$, which was considered a reasonable worst-case assumption.

Several factors influence bulk density (e.g. organic carbon content, particle size distribution, depth in soil). However, pesticide leaching is quite insensitive to bulk density. The simple function for estimating bulk density from the organic carbon content derived by Bergkvist and Jarvis (2004), was therefore judged adequate for our purpose.

\section{References}

AGRITOX - Base de données sur les substances actives phytopharmaceutiques. Home page. (online), available from: http://www.dive. afssa.fr/agritox/index.php (11.11.11).

Agreste, 2010. Mémento de la statistique agricole. France ed. 2010. Ministère de l'Agriculture, de l'Alimentation, de la Pêche, 35 pp.

Alletto, L., Coquet, Y., Benoit, P., Heddadj, D., Barriuso, E., 2010. Tillage management effects on pesticide fate in soils. A review. Agronomy for Sustainable Development 30, 367-400.

Arregui, M.C., Sanchez, D., Althaus, R., Scotta, R.R., Bertolaccini, I., 2010. Assessing the risk of pesticide environmental impact in several Argentinian cropping systems with a fuzzy expert indicator. Pest Management Science 66, 736-740.

Assaghir Z., 2010. Analyse formelle et fusion des informations: application à l'estimation et au contrôle d'incertitude des indicateurs agrienvironnementaux: Doctorat INPL, Institut National Polytechnique de Lorraine, UMR Nancy-Université - INRA 1121, Nancy, 153 pp.

Babuška, R., Verbruggen, H., 2003. Neuro-fuzzy methods for non-linear system identification. Annual Reviews in Control 27, 73-85.

Bergkvist, P., Jarvis, N., 2004. Modeling organic carbon dynamics and cadmium fate in long-term sludge-amended soil. Journal of Environmental Quality 33, 181-191.

Beven, K., Germann, P., 1982. Macropores and water-flow in soils. Water Resources Research 18,1311-1325.

Blenkinsop, S., Fowler, H.J., Dubus, I.G., Nolan, B.T., Hollis, J.M., 2008. Developing climatic scenarios for pesticide fate modelling in Europe. Environmental Pollution $154,219-231$.

Bockstaller, C., Girardin, P., van der Werf, H.M.G., 1997. Use of agro-ecological indicators for the evaluation of farming systems. European Journal of Agronomy 7, 261-270.

Bockstaller, C., Girardin, P., 2003. How to validate environmental indicators. Agricultural Systems 76, 639-653.

Bockstaller, C., 2004. Elaboration et utilisation des indicateurs. Exemple de I-Phy. In: Barriuso, E. (Ed.), Estimation des risques environnementaux des pesticides: un point sur. INRA Editions, Paris, pp. 75-86.

Bockstaller, C., Guichard, L., Makowski, D., Aveline, A., Girardin, P., Plantureux, S., 2008a. Agri-environmental indicators to assess cropping and farming systems. A review. Agronomy for Sustainable Development 28, 139-149.

Bockstaller, C.,Wohlfahrt, J., Huber, A., Hennebert, P., Zahm, F., Vernier, F., Keichinger, O., Girardin, P., 2008. Les indicateurs de risque de transfert de produits phytosanitaires et leur validation: exemple de l'indicateur I-PHY. Ingénieries, no. $86,103-114$

Bockstaller, C., Guichard, L., Keichinger, O., Girardin, P., Galan, M.B., Gaillard, G., 2009. Comparison of methods to assess the sustainability of agricultural systems. A review. Agronomy for Sustainable Development 29, 223-235.

Boesten, J.J.T.I., van der Linden, A.M.A., 1991. Modeling the influence of sorption and transformation on pesticide leaching and persistence. Journal of Environmental Quality 20, 425-435.

Bouzaher, A., Lakshminarayan, P.G., Cabe, R., Carriquiry, A., Gassman, P.W., Shogren, J.F., 1993. Metamodels and nonpoint pollution policy in agriculture. Water Resources Research 29, 1579-1587.

Bues, R., Bussieres, P., Dadomo, M., Dumas, Y., Garcia-Pomar, M.I., Lyannaz, J.P., 2004. Assessing the environmental impacts of pesticides used on processing tomato crops. Agriculture, Ecosystems and Environment 102, 155-162.

Carsel, R.F., Imhoff, J.C., Hummel, P.R., Cheplick, J.M., Donigian, A.S.J., 2003. PRZM-3, A model for predicting pesticide and nitrogen fate in the crop root and unsaturated soil zones: User's manual for release 3. 12. National Exposure Research Laboratory, Office of Research and Development, USEPA, Athens, GA.
Centofanti, T., Hollis, J.M., Blenkinsop, S., Fowler, H.J., Truckell, I., Dubus, I.G., Reichenberyer, S., 2008. Development of agro-environmental scenarios to support pesticide risk assessment in Europe. Science of the Total Environment 407, 574-588.

Chikowo, R., Faloya, V., Petit, S., Munier-Jolain, N.M., 2009. Integrated Weed Management systems allow reduced reliance on herbicides and long-term weed control. Agriculture, Ecosystems and Environment 132, 237-242.

Choisnel, E., Noilhan, J., 1995. La prévision des sécheresses,; 1; La recherche, no. 272, pp. 34-40.

Commission of the European Communities (CEC), 1985. Soil Map of the European Communities at $1: 1,000,000$ scale. Office for the Official Publications of the European Communities, Luxembourg, 124 pp.

Dean, J.D., Huyakorn, P.S., Donigian, A.S., Voos, K.A., Schanz, R.W., Carsel, R.F., 1989. Risk of unsaturated/saturated transport and transformation of chemical concentrations (RUSTIC), vol. II, User's guide. Rep. U.S. EPA/600/3-89/048b, Environmental Protection Agency, Washington, D.C.

Dekker, L.W., Ritsema, C.J., 1996. Uneven moisture patterns in water repellent soils. Geoderma 70, 87-99.

ENDURE - European Network for the Durable Exploitation of Crop Protection Strategies. Home page (online) (23.08.11), available from: http://www.endurenetwork.eu/ (11.11.11).

European Union, 1991. Council Directive 91/414/EEC of 15 July 1991 concerning the placing of plant protection products on the market, Official Journal of the European Union 230, (19.8.1991).

Flury, M., 1996. Experimental evidence of transport of pesticides through field soils-a review. Journal of Environmental Quality 25, 25-45.

FOCUS, 2000. FOCUS groundwater scenarios in the EU plant production review process. Report of the FOCUS Groundwater Scenarios Workgroup. EC Document Reference, Sanco/321/2000.

FOOTPRINT - Functional tools for pesticide risk assessment and management. Home page (online) (06.08.10), available from: http://www.eu-footprint.org (11.11.11).

Fragoulis, G., Trevisan, M., Di Guardo, A., Sorce, A., van der Meer, M., Weibel, F., Capri, E., 2009. Development of a management tool to indicate the environmental impact of organic viticulture. Journal of Environmental Quality 38, 826-835.

Germann, P.F., 1985. Kinematic wave approach to infiltration and drainage into and from soil macropores. Transactions of the American Society of Agricultural Engineers 28, 745-749.

Gustafson, D.I., 1989. Groundwater ubiquity score-a simple method for assessing pesticide leachability. Environmental Toxicology and Chemistry 8, 339-357.

Hill, D.E., Parlange, J.Y., 1972. Wetting front instability in layered soils. Proceedings of the Soil Science Society of America 36, 697-702.

Holman, I.P., Dubus, I.G., Hollis, J.M., Brown, C.D., 2004. Using a linked soil model emulator and unsaturated zone leaching model to account for preferential flow when assessing the spatially distributed risk of pesticide leaching to groundwater in England and Wales. Science of the Total Environment 318, 73-88.

Jarvis, N., 1994. The MACRO model (version 3.1) technical description and sample simulations. Reports and Dissertations. Swedish University of Agricultural Sciences, Uppsala, 19.

Jarvis, N.J., Zavattaro, L., Rajkai, K., Reynolds, W.D., Olsen, P.A., McGechan, M., Mecke, M., Mohanty, B., Leeds-Harrison, P.B., Jacques, D., 2002. Indirect estimation of near-saturated hydraulic conductivity from readily available soil information. Geoderma 108, 1-17.

Jarvis, N.J., 2007. A review of non-equilibrium water flow and solute transport in soil macropores: principles, controlling factors and consequences for water quality. European Journal of Soil Science 58, 523-546.

Jarvis, N., Lindahl, A., Messing, I., Stenemo, F., Hollis, J., Reichenberger, S., Dubus, I.G., 2007. Algorithm to completely parameterize MACRO from basic soil property data. Report DL21 of the FP6 EU-funded FOOTPRINT project, 18 pp. (www.eufootprint.org)

Jarvis, N., 2008. Near-saturated hydraulic properties of macroporous soils. Vadose Zone Journal 7, 1256-1264.

Jarvis, N., Moeys, J., Hollis, J.M. Preferential flow in a pedological perspective. In: Lin, H. (Ed.) Hydropedology: Synergistic Integration of Soil Science and Hydrology. Elsevier, in press.

Kjaer, J., Olsen, P., Ullum, M., Grant, R., 2005. Leaching of glyphosate and amino-methylphosphonic acid from Danish agricultural field sites. Journal of Environmental Quality 34, 608-620.

Kladivko, E.J., Van Scoyoc, G.E., Monke, E.J., Oates, K.M., Pask, W., 1991. Pesticide and nutrient movement into subsurface tile drains on a silt loam soil in Indiana. Journal of Environmental Quality 20, 264-270.

Kung, K.J.S., 1990. Preferential flow in a sandy vadose zone. 1. Field observation. Geoderma 46, 51-58.

Köhne, J.M., Köhne, S., Šimůnek, J., 2009. A review of model applications for structured soils: a) water flow and tracer transport. Journal of Contaminant Hydrology $104,4-35$.

Larsbo, M., Roulier, S., Stenemo, F., Kasteel, R., Jarvis, N., 2005. An improved dualpermeability model of water flow and solute transport in the vadose zone. Vadose Zone Journal 4, 398-406.

Larsson, M.H., Jarvis, N.J., 2000. Quantifying interactions between compound properties and macropore flow effects on pesticide leaching. Pest Management Science $56,133-141$.

Lewan, E., Kreuger, J., Jarvis, N., 2009. Implications of precipitation patterns and antecedent soil water content for leaching of pesticides from arable land. Agricultural Water Management 96, 1633-1640. 
Lewis, K.A., Newbold, M.J., Tzilivakis, J., 1999. Developing an emissions inventory from farm data. Journal of Environ Management 55, 183-197.

Levitan, L., 2000. How to and why: assessing the enviro-social impacts of pesticides. Crop Protection 19, 629-636.

Lindahl, A.M.L., Dubus, I.G., Jarvis, N.J., 2009. Site classification to predict the abundance of the deep-burrowing earthworm Lumbricus terrestris L. Vadose Zone Journal 8, 911-915.

MathWorks, T., 2002. Fuzzy Logic Toolbox for Use With MATLAB. User's Guide, Version 2. The MathWorks Inc., Natick, Massachusetts.

Maud, J., Edwards-Jones, G., Quin, F., 2001. Comparative evaluation of pesticide risk indices for policy development and assessment in the United Kingdom. Agriculture, Ecosystems and Environment 86, 59-73.

McGrath, G.S., Hinz, C., Sivapalan, M., 2008. Modelling the impact of within-storm variability of rainfall on the loading of solutes to preferential flow pathways. European Journal of Soil Science 59, 24-33.

Nolan, B.T., Dubus, I.G., Surdyk, N., Fowler, H.J., Burton, A., Hollis, J.M., Reichenberger, S., Jarvis, N.J., 2008. Identification of key climatic factors regulating the transport of pesticides in leaching and to tile drains. Pest Management Science 64, 933-944.

Novak, S., Moretty, P., Villard, A., 2009. Quels outils pour construire un plan d'action destiné à limiter les pollutions diffuses par les pesticides? L'exemple de Laives Ingénieries, 59-60, 55-70.

Olsson, J., 1998. Evaluation of a scaling cascade model for temporal rainfall disaggregation. Hydrology and Earth System Sciences 2, 19-30.

Perrin, R.M., 1997. Crop protection: taking stock for the new millennium. Crop Protection $16,449-456$

Piñeros Garcet, J.D., Ordoñez, A., Roosen, J., Vanclooster, M., 2006. Metamodelling: theory, concepts and application to nitrate leaching modelling. Ecological Modelling 193, 629-644.

Prato, T., 2005. A fuzzy logic approach for evaluating ecosystem sustainability. Ecological Modelling 187, 361-368.

Réal, B., 2004. Démarche proposée par le CORPEN pour l'estimation des risques de contamination des eaux. In: Barriuso, E. (Ed.), Estimation des risques environnementaux des pesticides: un point sur. INRA Editions, Paris, pp. 87-103.

Reichenberger, S., Amelung, W., Laabs, V., Pinto, A., Totsche, K.U., Zech, W., 2002. Pesticide displacement along preferential flow pathways in a Brazilian oxisol. Geoderma 110, 63-86.

Reus, J.A.W.A., Leendertse, P.C., 2000. The environmental yardstick for pesticides: a practical indicator used in the Netherlands. Crop Protection 19,637-641.

Reus, J., Leendertse, P., Bockstaller, C., Fomsgaard, I., Gutsche, V., Lewis, K., Nilsson, C., Pussemier, L., Trevisan, M., van der Werf, H., Alfarroba, F., Blümel, S., Isart,
J., McGrath, D., Seppälä, T., 2002. Comparison and evaluation of eight pesticide environmental risk indicators developed in Europe and recommendations for future use. Agriculture, Ecosystems and Environment 90, 177-187.

Richards, L.A., 1931. Capillary conduction of liquids through porous mediums. Physics 1, 318-333.

Ritsema, C.J., Dekker, L.W., Hendrickx, J.M.H., Hamminga, W., 1993. Preferential flow mechanism in a water repellent sandy soil. Water Resources and Research 29 2183-2193.

Shirazi, M.A., Boersma, L., 1984. A unifying quantitative-analysis of soil texture. Soi Science Society of America Journal 48, 142-147.

Stenemo, F., Lindahl, A.M.L., Gärdenäs, A., Jarvis, N., 2007. Meta-modeling of the pesticide fate model MACRO for groundwater exposure assessments using artificial neural networks. Journal of Contaminant Hydrology 93, 270-283.

Sugeno, M., 1985. Industrial Applications of Fuzzy Control. Elsevier Science, Amsterdam.

Tomlin, C.D.S., 2009. The Pesticide Manual, 15th ed. BCPC Publication, Alton, Hamp shire, UK.

Traub-Eberhard, U., Kördel, W., Klein, W., 1994. Pesticide movement into subsurface drains on a loamy silt soil. Chemosphere 28, 273-284.

USDA - United States Department of Agriculture. Soil texture calculator. Home page (online), available from: http://soils.usda.gov/technical/ aids/investigations/texture (11.11.11).

van der Werf, H.M.G., Zimmer, C., 1998. An indicator of pesticide environmenta impact based on a fuzzy expert system. Chemosphere 36, 2225-2249.

van Genuchten, M.T., Wierenga, P.J., 1976. Mass transfer studies in sorbing porous media. I. Analytical solutions. Soil Science Society of America Journal 40 473-480.

van Genuchten, M.T., 1980. A closed-form equation for predicting the hydraulic conductivity of unsaturated soils. Soil Science Society of America Journal 44 892-898.

Vereecken, H., 2005. Mobility and leaching of glyphosate: a review. Pest Management Science 61, 1139-1151.

Wohlfahrt, J., 2008. Développement d'un indicateur d'exposition des eaux de surface aux pertes de pesticides à l'échelle du bassin versant Doctorat INPL thesis, Institut National Polytechnique de Lorraine, UMR Nancy-Université - INRA 1121 Nancy, 197 pp.

Wösten, J.H.M., Lilly, A., Nemes, A., Le Bas, C., 1998. Using existing soil data to derive hydraulic parameters for simulation models in environmental studies and in land use planning. Report, vol. 156, DLO-Staring Centre, Wageningen, the Netherlands. 